\title{
Evaluation of Ability of Two Different Pneumatic Boxing Gloves to Reduce Delivered Impact Forces and Improve Safety
}

\author{
Paul Perkins ${ }^{1,2}$, Alex Jamieson'1, Wayne Spratford ${ }^{1}$, Allan Hahn1,3,4,5 \\ ${ }^{1}$ University of Canberra Research Institute for Sport and Exercise, Canberra, Australia \\ ${ }^{2}$ Boxing Australia Limited, Canberra, Australia \\ ${ }^{3}$ Queensland Academy of Sport, Brisbane, Australia \\ ${ }^{4}$ Griffith University School of Engineering, Brisbane, Australia \\ ${ }^{5}$ Australian Institute of Sport, Canberra, Australia \\ Email: paul.perkins@boxing.org.au
}

How to cite this paper: Perkins, P., Jamieson, A., Spratford, W. and Hahn, A. (2018) Evaluation of Ability of Two Different Pneumatic Boxing Gloves to Reduce Delivered Impact Forces and Improve Safety. World Journal of Engineering and Technology, 6, 457-491.

https://doi.org/10.4236/wjet.2018.62028

Received: May 3, 2018

Accepted: May 28, 2018

Published: May 31, 2018

Copyright $\odot 2018$ by authors and Scientific Research Publishing Inc. This work is licensed under the Creative Commons Attribution International License (CC BY 4.0).

http://creativecommons.org/licenses/by/4.0/

\begin{abstract}
Two prototype pneumatic boxing gloves of different design were compared against conventional $10 \mathrm{oz}($ Std $10 \mathrm{oz})$ and $16 \mathrm{oz}($ Std $16 \mathrm{oz}$ ) gloves in terms of ability to reduce impact forces delivered to a target. One of the pneumatic gloves (SBLI) contained a sealed air bladder inflated to a pressure of $2 \mathrm{kPa}$. The other (ARLI) incorporated a bladder that allowed release of air to the external environment upon contact with a target, followed by rapid air reuptake. Each glove was placed on to a mechanical fist and dropped 10 times on to an in-floor force plate from each of nine heights ranging from 1.0 to 5.0 metres, with the 5-metre drop generating a peak pre-impact glove velocity close to the reported maximum for elite boxers. Compared to the conventional gloves, the ARLI glove substantially reduced peak impact forces at all drop heights, with the reduction exceeding $30 \%$ even at the 5-metre level. The SBLI glove was as effective as the ARLI glove in reducing peak impact forces at drop heights of up to 2.5 metres, but its performance then progressively diminished, and at drop heights of 4.0, 4.5 and 5.0 metres it produced peak force readings similar to those recorded for the Std $10 \mathrm{oz}$ and Std $16 \mathrm{oz}$ gloves. The superiority of the ARLI glove was even more evident in relation to peak rate of force development, with reductions relative to the Std $10 \mathrm{oz}$ glove being $\sim 60 \%$ at drop heights up to 3.5 metres and still $\sim 47 \%$ at 5 metres. Peak rate of force development for the SBLI glove exceeded that for the ARLI glove for all drop heights of 2.0 metres and above, and at 4.0, 4.5 and 5.0 metres it was higher than the readings for the Std $10 \mathrm{oz}$ and $16 \mathrm{oz}$ gloves. The protective effect of the ARLI glove was associated with an increase in impact compliance and prolongation of contact time between glove and target. It is concluded that a
\end{abstract}


pneumatic boxing glove that provides for air exchange with the external environment can greatly reduce impact magnitudes across the whole range of pre-impact glove velocities likely to be encountered in boxing, thereby mitigating risks associated with the sport. While acceptance of the gloves by the boxing community is uncertain, opportunity may exist for almost immediate uptake in modified boxing programs.

\section{Keywords}

Boxing, Boxing Safety, Box'Tag, Modifed Boxing, ModBox, Pneumatic Boxing Glove, Sport Technology

\section{Introduction}

The sport of boxing has been subject to criticism on various grounds. Its safety is a central concern, with 1216 boxers (923 professionals, 293 amateurs) known to have died during the period between 1890 and 2007 from acute injuries received [1], and increasing evidence that there is a dose-response relationship between exposure to repeated head impacts and the occurrence of chronic traumatic brain injury that can produce serious functional disorders such as dementia, Parkinson's disease, compromised cognition, slurred speech, unsteady gait, depression and irrational anger [2] [3] [4] [5]. Although the incidence of chronic traumatic brain injury is higher in professional than amateur boxing because of the longer duration of professional contests, magnetic resonance imaging reportedly shows discernible structural anomalies in the brains of $\sim 11 \%$ of amateur boxers [6].

Another common argument against boxing is that it entails fundamental intent of contestants to harm each other by delivering blows so forceful that they have potential to cause loss of consciousness, and that injury therefore cannot be considered accidental [7] [8]. There have also been claims that boxing has negative social effects through exploitation of vulnerable young people [9] [10] [11] and glamorising of violence [12].

In view of the objections, medical authorities have called for boxing to be banned [13] [14] [15] [16] [17]. In two Scandinavian countries, bans on professional boxing were actually implemented 35 - 50 years ago but later rescinded [13] [14]. Some commentators see prohibition as an anti-libertarian option that would serve only to drive the sport underground where it would operate in a much less regulated environment [15] [16]. These commentators contend that cooperative development and deployment of risk mitigation strategies is likely to be a more efficacious approach. There have been suggestions that risk reduction could be accomplished through modification to boxing gloves used in contests [17]. Gloves are readily available in different sizes, with masses ranging from 8 oz to $20 \mathrm{oz}$ ( 227 to $567 \mathrm{~g}$ ). Generally, greater mass corresponds to more padding. Over recent years, there has been a small shift toward use of heavier gloves 
in competition in an attempt to promote safety. Since 2013, amateur boxers competing in weight divisions with an upper limit of $64.1 \mathrm{~kg}$ and above have been required to use $12 \mathrm{oz}$ gloves [18], whereas previously $10 \mathrm{oz}$ gloves were used in all weight divisions. Similarly, professional boxers in the heavier weight divisions now wear $10 \mathrm{oz}$ gloves, while those in lighter divisions continue to use $8 \mathrm{oz}$ gloves [18]. Scope exists for further shifts since boxers routinely use $14 \mathrm{oz}$ or $16 \mathrm{oz}$ gloves in sparring [19], but no scientific information is presently available concerning the extent to which heavier gloves with more padding alter peak impact forces.

Historically, several attempts have been made to produce gloves with novel characteristics aimed at improving safety. For example, thumbless gloves designed to prevent eye injuries caused by thumbs have been manufactured [20] [21] [22] and employed in competitive settings [23]. Additionally, efforts have been made to develop gloves capable of damping impact forces delivered to an opponent. Such efforts have included the use of intra-glove elastic restraints to impede forward movement of the fist within its glove cavity [24]. There has even been a prototype "Uni Boxing Glove" that effectively joins left and right gloves together, so that users are required to punch with both hands simultaneously and therefore have limited capacity for force generation [25].

The most common approach to design of impact-damping gloves, however, has entailed replacement of standard padding with air. Beginning from the 1890 s, at least 20 patents have been registered for pneumatic or air-inflated boxing gloves [26]-[45], with a minimum of one in every decade except the 1980s. Numerous novel concepts have been incorporated. One inventor, Joseph Slizus of Seattle, USA, obtained three patents spanning a period of 28 years [33] [35] [41], progressively addressing problems encountered in practical experimentation with the gloves, and a Finnish physician, Lyderik Löfgren, pursued development and uptake of pneumatic gloves for at least seven years [46] [47]. The gloves produced by Löfgren were subjected to laboratory testing which showed that, compared to standard gloves, they substantially reduced acceleration of a struck mass attached to a pendulum, with the protective effect increasing as a function of impact force and as the glove air pressure was increased from 3.5 to $20.5 \mathrm{kPa}$ [46] [47].

To date, neither the pneumatic gloves nor any of the other novel gloves have achieved sustained acceptance and uptake by the boxing community. The reasons for this are unknown but undoubtedly reflect the difficulty of changing established practice in a sport with a long history and strong traditions.

During the past decade, modified forms of boxing that emphasise safety have emerged in Australia [48] and elsewhere [49]. It is conceivable that the communities participating in these forms of the sport might be more receptive than conventional boxers to the use of modified equipment, and that this could eventually provide a pathway to wider uptake.

Accordingly, we have worked in the context of a modified boxing program to develop, test and iteratively refine gloves capable of substantially reducing peak 
impact forces delivered to an opponent. We have actively sought to maximise both the effectiveness of the gloves in impact buffering and their attractiveness to users. This paper reports on the laboratory evaluation of two specific prototypes.

\section{Method}

An apparatus allowing the dropping of gloves containing a mechanical fist on to an in-floor Kistler force plate (Kistler, Amherst, MA, USA) was used to compare the two prototype low-impact gloves against standard $10 \mathrm{oz}$ (Std $10 \mathrm{oz}$ ) and 16 oz (Std $16 \mathrm{oz}$ ) gloves commonly used by boxers. One of the prototypes incorporated a sealed air-filled bladder as its primary cushioning element and is hereafter identified by the abbreviation SBLI (Sealed Bladder Low-Impact). The other incorporated a bladder that enabled rapid release of air to the external environment upon contact of the glove with a target, and subsequent rapid air return. It is hereafter identified by the abbreviation ARLI (Air-Release Low-Impact).

\subsection{Construction of SBLI Glove}

The fundamental aspects of construction of the SBLI glove are illustrated in Figure 1. A latex bladder from a small soccer ball was cross-sectionally cut at the point indicated by the red line in the figure. The cut was made parallel to the orientation of the valve used for bladder inflation. The open end of the bladder was then sealed by means of a truck tyre patch that was glued into position. This effectively created a bladder of hemispherical shape. The bladder was then positioned in a leather casing that had open-cell urethane foam on its inner surface, enabling formation of an intact thumbless glove into which a closed fist could be inserted to sit immediately behind the bladder, such that the whole bladder was located between the fist and the glove target. The position of the bladder is shown by the blue outline in panel $d$ of Figure 1 . The bladder valve was juxtaposed with an opening on the under-surface of the glove casing so that the glove could be inflated and deflated using a conventional bicycle tyre pump. For the purposes of the testing, the bladder was inflated to a pressure of $2 \mathrm{kPa}$ as measured using a Ross Brown model KPCh low-pressure gauge with a range of 0 - 10 $\mathrm{kPa}$.

\subsection{Construction of ARLI Glove}

In this design the bladder was provided with a resilient, elastic internal 'skeleton' that could collapse under conditions of high internal pressure during impact but would immediately recover its shape thereafter, with the recovery causing the internal bladder pressure to fall temporarily below the ambient pressure, so driving air inflow. Figure 2 shows the components of this bladder and the product of their assembly.

The internal skeleton consisted of a "ball" of high-density, medium-firmness open cell foam (Joyce Foam Products HR 36-140), which was placed inside the 

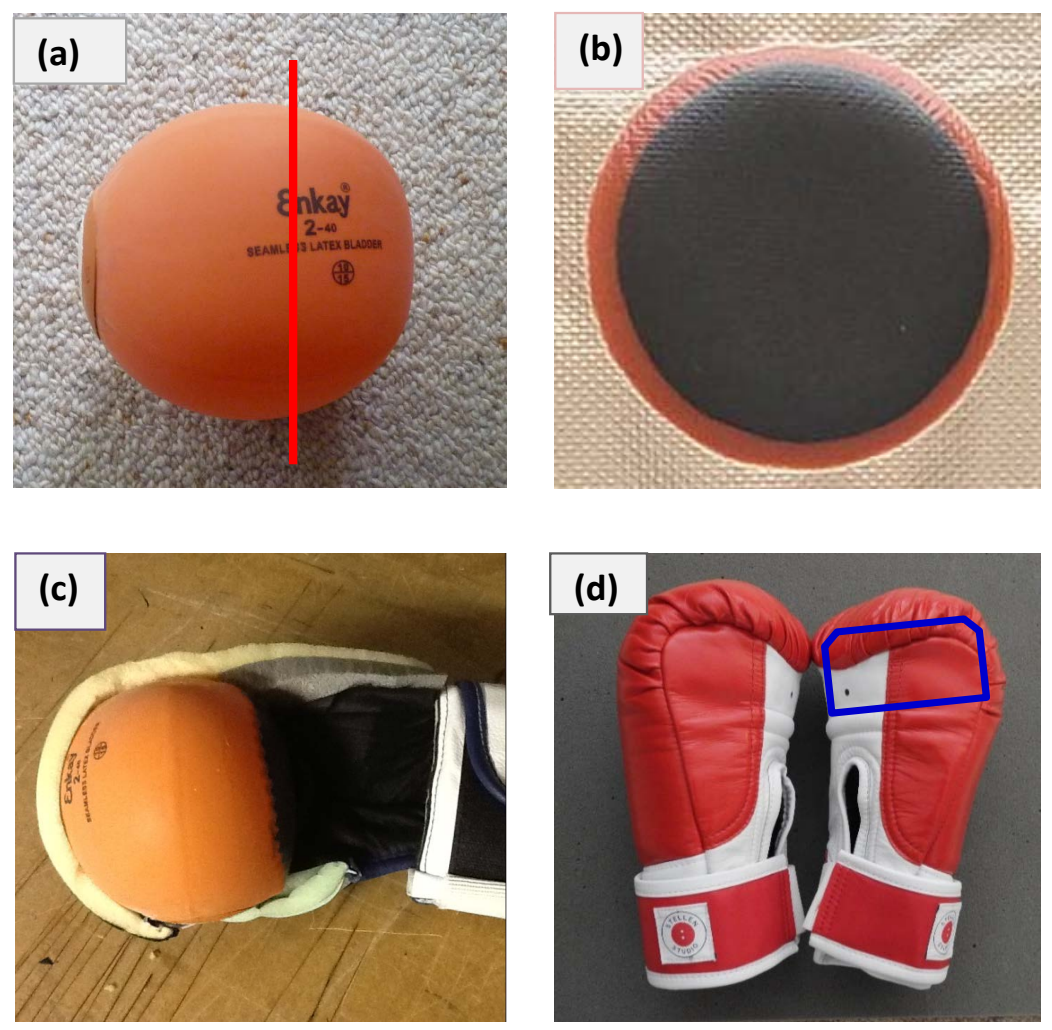

Figure 1. Basic elements of SBLI glove. $(a)=$ Small soccer ball bladder with red line indicating where the bladder was cut, $(b)=$ Truck tyre patch used to seal the bladder after cutting to create hemispherical shape, (c) = longitudinal view of glove showing position of bladder within glove casing and fist compartment behind bladder, (d) = Intact gloves with leather casing in place and blue outline illustrating location of bladder. Note that upper portion of white region of gloves includes openings allowing inflation and deflation of the sealed bladder by use of a bicycle pump and needle valve.
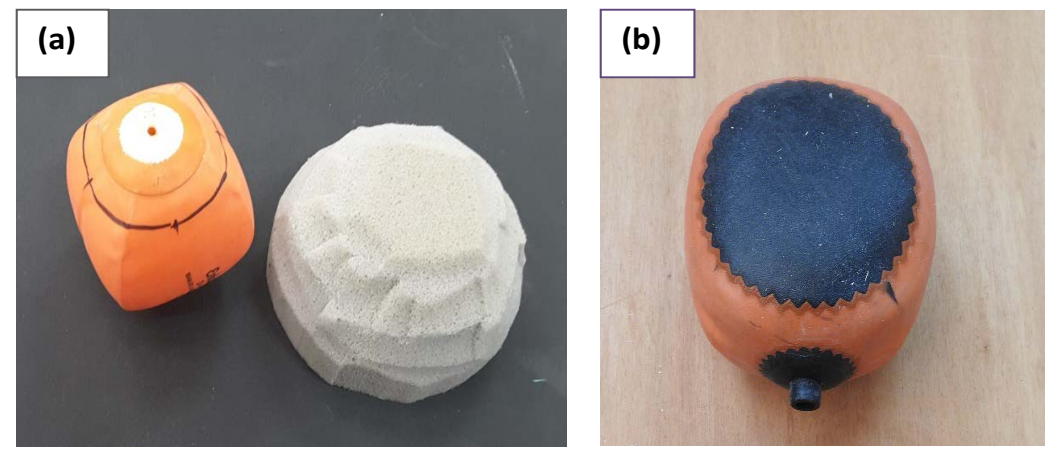

Figure 2. Bladder for ARLI glove with capability for air release. The bladder in (panel a) was cut at the point indicated by the black line. The foam skeleton was then inserted and the unit was sealed with a truck tyre patch (panel b). A port to allow air egress and ingress (panel b) was then added.

bladder prior to sealing with the truck tyre patch. A hole was then made in the bladder and a plastic tube with an internal diameter of $10 \mathrm{~mm}$ was inserted. Thereafter, the area around the insertion was then sealed. 
The bladder was then integrated into a whole, thumbless glove in a way that that allowed location of the air vent on the palmar glove surface (Figure 3 ).

\subsection{Std $10 \mathrm{oz}$ and Std $16 \mathrm{oz}$ Gloves}

The Std $10 \mathrm{oz}$ and Std $16 \mathrm{oz}$ gloves used for comparison with the SBLI and ARLI gloves were manufactured by Sting Sports (Melbourne, Australia), which was the official supplier of boxing gloves for the 2014 Commonwealth Games and the 2016 Olympic Games. The gloves evaluated were of the type used by elite amateur boxers in competition and training.

\subsection{Mechanical Fist}

A prerequisite to our experiment was the development of a mechanical fist that could be inserted into gloves to properly simulate real-world practice for different glove types. This meant that it had to cater for the Std $10 \mathrm{oz}$ and Std $16 \mathrm{oz}$ gloves to be put on with fingers extended, and the fist subsequently clenched, and for SBLI and ARLI gloves to be put on with the fist already in the clenched position. The mechanical fist was designed and constructed to our specifications by a Melbourne-based team consisting of an engineer and an aircraft mechanic. As illustrated in Figure 4, it consisted of three metal sections hinged together to simulate the long axis of the forearm, the proximal section of the fingers and the distal sections of the fingers. It incorporated a ratchet system for clenching the fist and locking it firmly in the clenched position. The centre of mass of the clenched fist was aligned with the long axis of the unit.

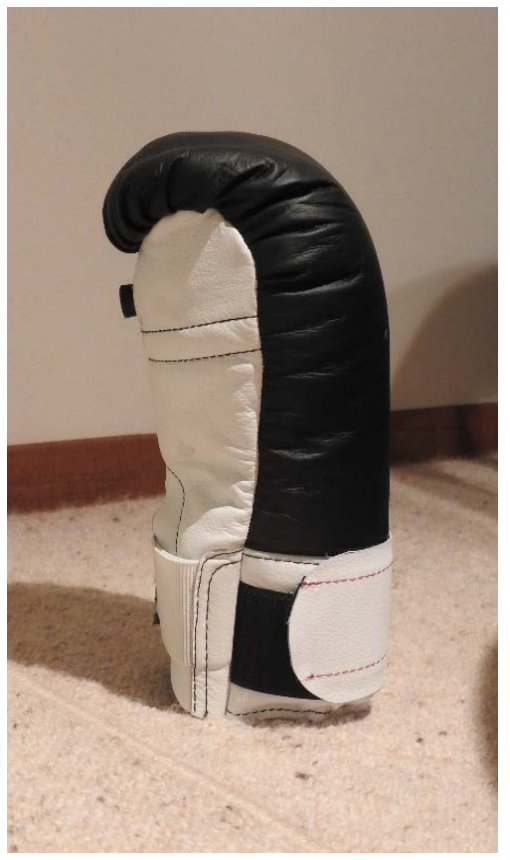

Figure 3. A prototype low-impact glove allowing air release and return. The port can be seen on the front surface of the glove toward the top. 

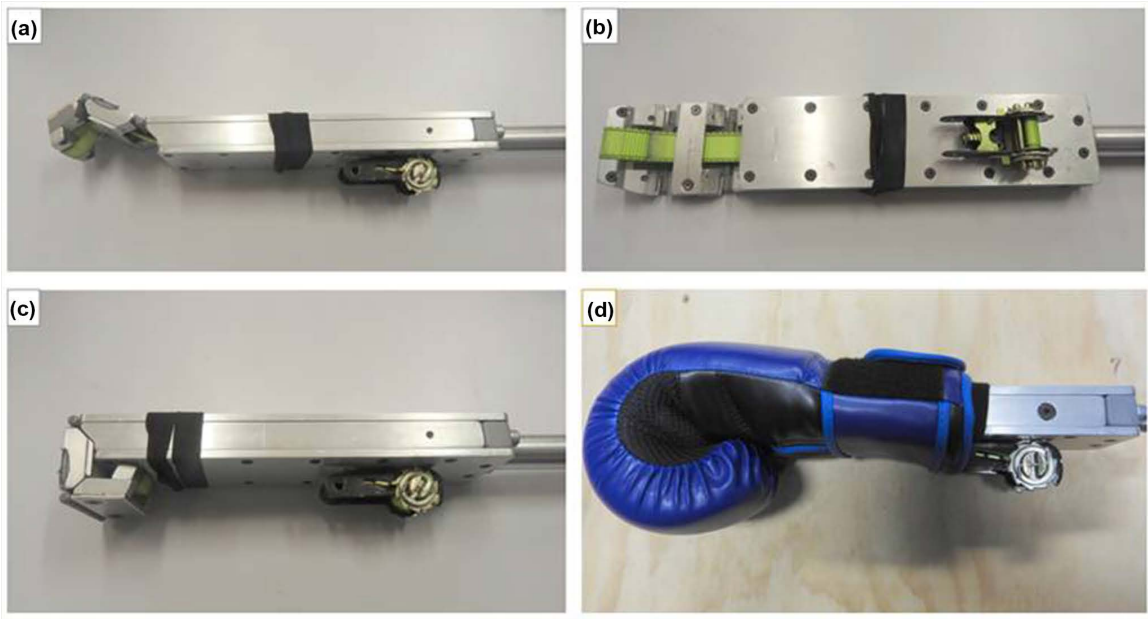

Figure 4. The mechanical fist used in the experiment. Panel (a) is a side view with the fist open and shows the three hinged metal sections of the device. Panel (b) is a view from underneath and shows the mechanism used to draw the fist closed. Panel (c) shows the fist locked in the closed position. Panel (d) shows the fist inside a glove and highlights the accuracy with which normal glove positioning on a fist was simulated.

The design of the mechanical fist was such that a rod made of high tensile steel could be securely screwed into it at the end opposite that designed to receive the gloves. At the other end of the rod was a hook for attachment of a cord forming part of the drop-testing apparatus. With the rod incorporated, the mechanical fist had a mass of $3.046 \mathrm{~kg}$ which, based on the findings of Walilko et al [50], is close to the effective mass associated with punches delivered by elite boxers.

\subsection{Experimental Configuration}

The drop testing apparatus employed in our experiment is shown in Figure 5. We calculated that a drop height of 5 metres should produce a pre-impact glove velocity of $9.90 \mathrm{~m} \cdot \mathrm{sec}^{-1}$ which is very close to the average maximum velocity reportedly achieved by elite boxers [50]. We were able to access an in-floor Kistler force plate (Kistler, Amherst, New York, USA) in a University of Canberra laboratory that had a ceiling height of more than 5 metres. In consultation with a Canberra-based company, AJA Engineering, we designed a pulley system to enable the drop testing experiments. A frame to support a low-friction, flanged pulley was constructed by AJA Engineering and installed in the laboratory. It included a bar that protruded outward from a wall mounting so that the pulley was positioned directly above the centre of the force plate at a height of 5.5 metres. A cord placed over the pulley allowed the gloves to be drawn up to any required drop height.

To elevate gloves to desired drop heights, the cord was manually pulled through an eyelet positioned at the top of a floor-mounted post. The cord was marked at intervals corresponding to half-metre increments in drop heights between 1 and 5 metres. Alignment of the marks with the eyelet on the post ensured accuracy of the drop heights. 


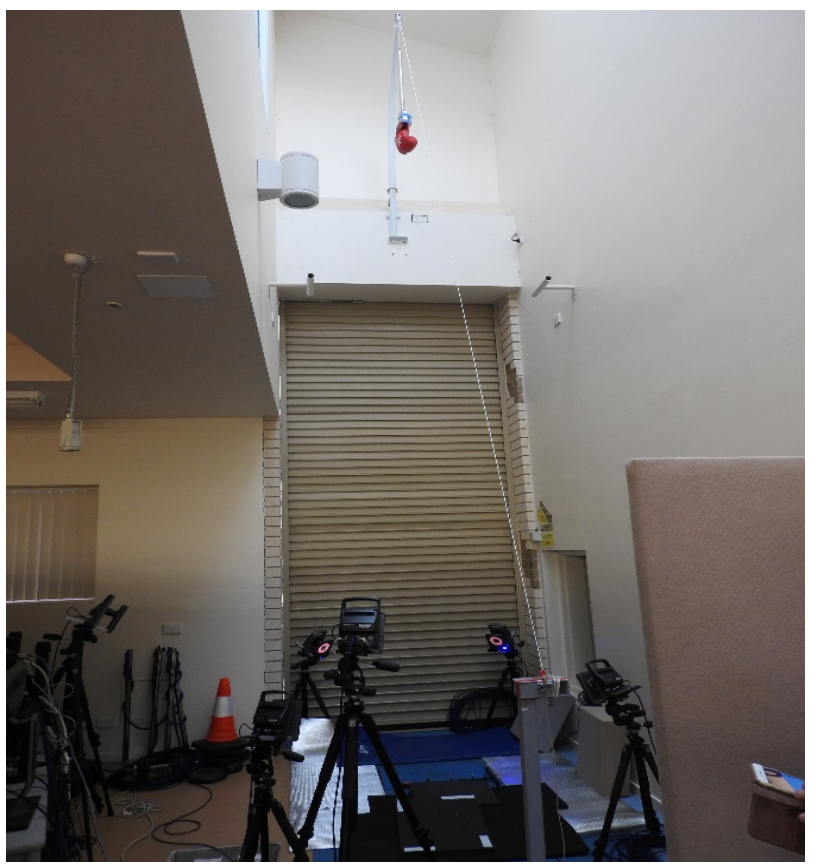

Figure 5. Drop testing system used for glove evaluation at the University of Canberra.

The force plate had a surface area of $600 \times 400 \mathrm{~mm}$. To protect against damage from glove impacts, it was covered by a $25 \mathrm{~mm}$ thick mat of Ultralon EVA 75 material with a guaranteed Shore A durometer hardness rating of $30-35$, which is at the upper end of the range for healthy human skin [51] [52] but well below the levels observed for human cortical and trabecular bone [53]. Outputs from the force plate were sampled at 10,000 $\mathrm{Hz}$.

A Vicon Motion Capture System (Oxford Metrics Ltd., Oxford, UK) with four cameras each sampling at 500 frames per second was used to determine glove velocities just before and after impact with the force plate. Markers were placed on gloves to enable determination of displacement and thus calculation of velocity over successive 2-msec time periods. Data from the four cameras were integrated to ensure the accuracy of the calculations and to obtain 3-dimensional images of glove trajectories.

Set-up of measurement parameters for the Kistler force plate and subsequent collection of data from the plate was accomplished via Vicon software run on a standard PC, permitting synchronization of force plate and Vicon data. Throughout all testing sessions, known masses were regularly placed on the force plate as a means of checking the accuracy of the force plate readings.

\subsection{Experimental Protocol}

The Std $10 \mathrm{oz}$, Std $16 \mathrm{oz}$, SBLI and ARLI gloves were each dropped 10 times on to the force plate from each of nine heights ranging from 1 to 5 metres, with increments of 0.5 metres. The testing was conducted over two sessions, separated by eight days. In the first session, drop heights ranged from 1.0 to 3.5 metres. 
For each glove, the initial drop height was 2.0 metres, and we then progressed sequentially to $2.5,1.5,1.0,3.0$ and 3.5 metres. The Std $10 \mathrm{oz}$ glove was tested first, followed by the SBLI, ARLI and Std $16 \mathrm{oz}$ gloves. In the second session, the order of drop test heights was 4.0, 4.5 and 5.0 metres, and the order of glove testing was ARLI, Std $10 \mathrm{oz}$, Std $16 \mathrm{oz}$, SBLI. In both sessions, each glove was tested at all drop heights before progression to the next glove.

\section{Results}

There was a tendency for peak force readings to increase over the course of a 10-drop series, and particularly over the first four drops. When data from all glove types and drop heights were combined to calculate overall mean peak forces for drops 1 - 10, there was a significant positive correlation $(\mathrm{r}=0.61, \mathrm{P}<$ 0.05 ) between drop number and peak force, and the correlation was even higher $(0.73, \mathrm{P}<0.01)$ when instead of arithmetic mean values for each drop number we used geometric means to minimise potential for over-representation of particular glove types or drop heights. To allow for this order effect, we calculated the peak force associated with any particular condition as the mean of the highest five readings obtained from the 10 drops.

The peak forces determined in the above way are presented in Figure 6. The two prototype pneumatic gloves provided similar protective effects up to and including a drop height of 2.5 metres. Beyond that point, the protection afforded by the SBLI glove progressively diminished, and at a drop height of 4.0 metres was gone. By contrast, the ARLI glove continued to give substantial protection, with the peak force readings at drop heights of 4.0, 4.5 and 5.0 metres all being lower than those for the Std 10 oz glove by $30 \%$.

The mean peak glove velocities for the various drop heights were close to expected values. Figure 7 shows that for any given combination of drop height and glove type, peak velocity measurements were highly repeatable. The mean peak velocities for the two pneumatic gloves were slightly less than those for the two conventional gloves. This may have been due to the padding of the pneumatic gloves extending further out from the mechanical fist than was the case for the conventional gloves, with the drop height therefore being marginally less. The readings for Std $10 \mathrm{oz}$ and Std $16 \mathrm{oz}$ gloves were very similar to each other, as were the readings for SBLI and ARLI gloves.

To correct for the differences in peak pre-impact glove velocities between glove types, peak force readings were plotted against the measured velocities.

Exponential regression curves were then fitted to the data for each glove type (Figure 8). The curves provided excellent description of the data, with $\mathrm{R}^{2}$ values exceeding 0.996 in each case. Calculations based on the exponential regression equations revealed that, compared to the Std $10 \mathrm{oz}$ glove, the ARLI glove substantially reduced peak impact forces for all pre-impact velocities. The reductions ranged from $37 \%$ at a velocity of $4.0 \mathrm{~m} \cdot \mathrm{sec}^{-1}$ to $25 \%$ at a velocity of 10.0 $\mathrm{m} \cdot \mathrm{sec}^{-1}$. The ARLI glove also decreased impact forces relative to those measured 


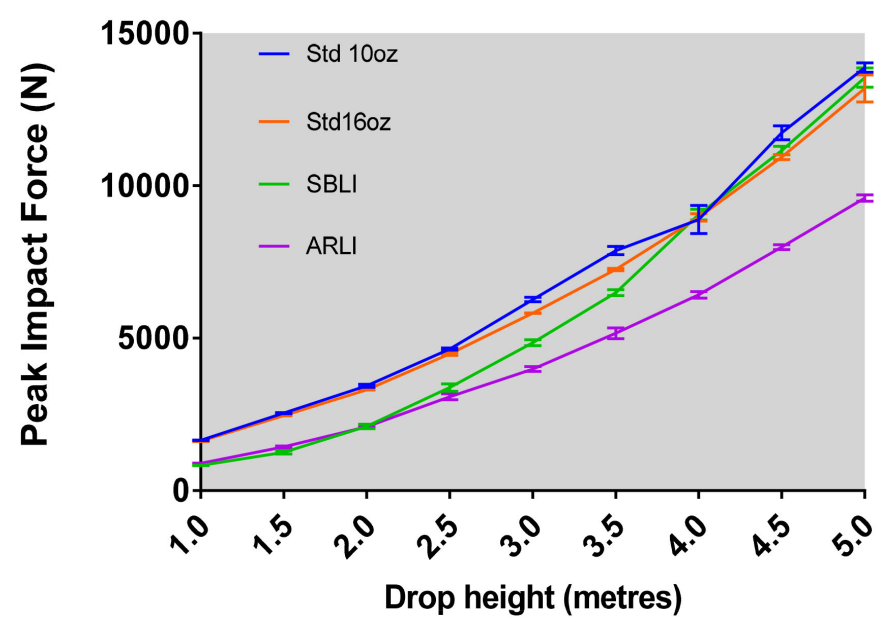

Figure 6. Peak impact force readings as a function of glove type and drop height. Each point on the graph is the mean of the highest five readings recorded in a series of 10 drops. Std $10 \mathrm{oz}=$ conventional $10 \mathrm{oz}$ boxing glove, Std $16 \mathrm{oz}=$ conventional $16 \mathrm{oz}$ boxing glove, SBLI = low-impact glove with sealed bladder, ARLI = low-impact glove with air release. Bars indicate standard deviations for the five readings under each condition.

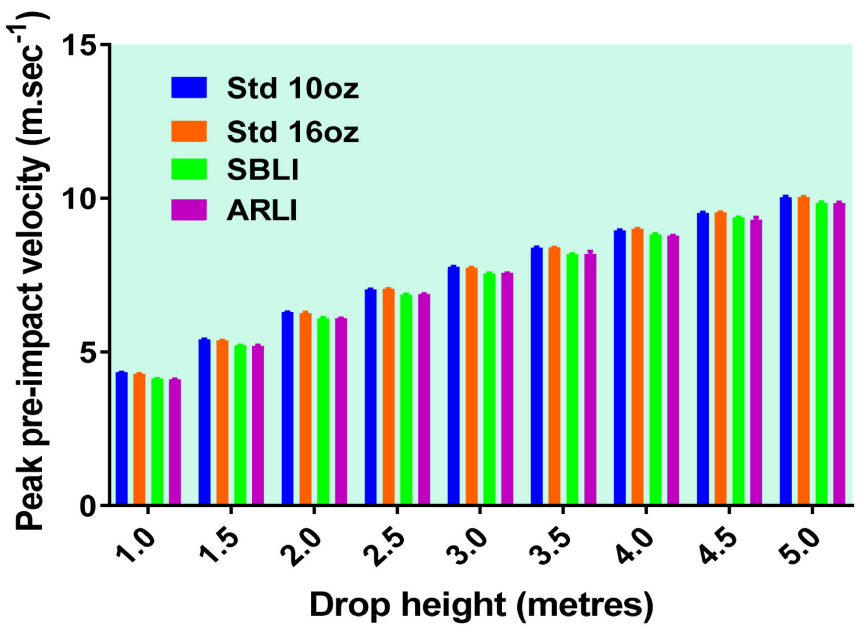

Figure 7. Pre-impact glove velocities for various glove types and drop heights. Each bar represents the mean of the five drops that produced the highest peak force readings from a total of 10 drops. Standard deviations for the five drops are also indicated Standard deviations for the five drops are also indicated but are so small as to be barely perceptible.

for the Std $16 \mathrm{oz}$ glove, with the magnitude of decrease being 35\% at a glove velocity of $4.0 \mathrm{~m} \cdot \mathrm{sec}^{-1}$ and $20 \%$ at $10 \mathrm{~m} \cdot \mathrm{sec}^{-1}$. This is salient since $16 \mathrm{oz}$ gloves are commonly used by boxers in sparring with a view to lowering impact forces [19]. The protective effect of the Std 16 oz glove tested in our experiment relative to the Std $10 \mathrm{oz}$ glove was very much less than that of the ARLI glove across a wide range of glove velocities. 


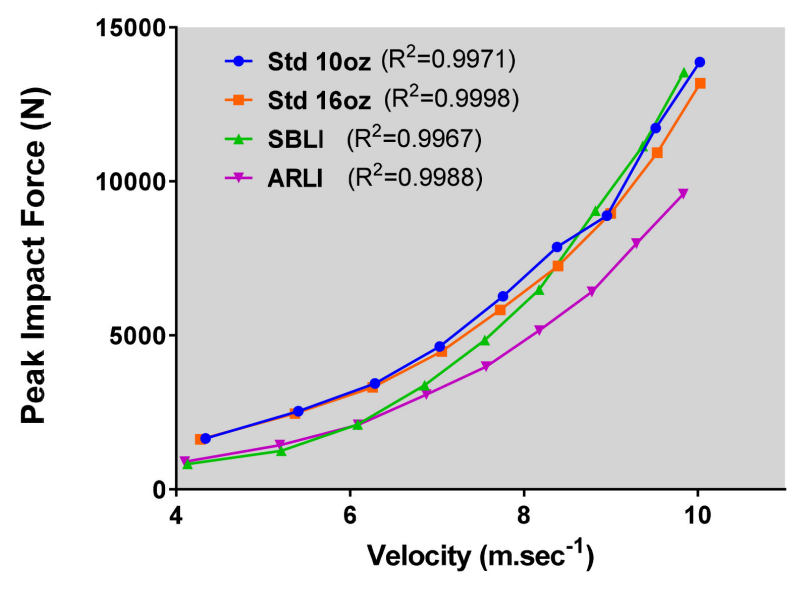

Figure 8. Effect of glove type on relationship between peak pre-impact glove velocity and peak impact force.

Figure 9 shows velocity measurements obtained from the Vicon Motion Capture System for 16 frames covering the period from just before to just after glove impact. Each curve represents an average for the five glove drops that produced the highest peak force values from an average of 10 drops. The velocities for the two low-impact glove types slowed much more gradually following contact. This affords some insight into the mechanism of peak force reduction, since it demonstrates "softer" initial collision between glove and target. The "rebound" in post-contact velocities for the Std $10 \mathrm{oz}$ and Std $16 \mathrm{oz}$ gloves following glove contact at the higher drop heights is indicative of velocities recorded in the upward direction as the glove bounced away from the force plate.

Contact times between glove and force plate are shown in Figure 10. The times were calculated as the period from when the force plate reading first reached and remained above $20 \mathrm{~N}$ in the ascending phase to when it became continuously less than $20 \mathrm{~N}$ in the descending phase. The threshold value of 20 $\mathrm{N}$ was set with a view to ensuring that detection of the beginning and end points of contact would not be contaminated by baseline noise in the electrical activity of the force plate and was based on advice from previous force plate users. Figure 10 demonstrates that, for all drop heights, contact time between glove and force plate was substantially longer for the prototype low-impact gloves (SBLI and ARLI) than for the conventional (Std $10 \mathrm{oz}$ and Std $16 \mathrm{oz}$ ) gloves.

While it could be expected that dissipation of force over a longer period would favour occurrence of lower peak forces, Figure 11-which shows force-time relationships recorded from the force plate-permits greater understanding of what transpired. The data presented relate to drops that produced the third highest peak force values within a series of ten (and therefore the median values for the five trials used to calculate representative peak force values for various conditions). At all drop heights, the curves for the Std $10 \mathrm{oz}$ and Std $16 \mathrm{oz}$ gloves closely resembled each other, being characterised by quite rapid rise in force following contact. By contrast, the curves for the two pneumatic gloves revealed that in the first few milliseconds post-contact there was very little increase in 


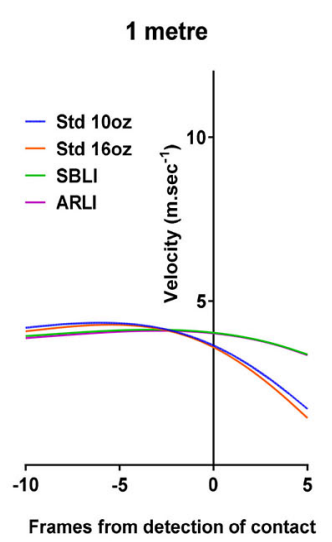

2.5 metres

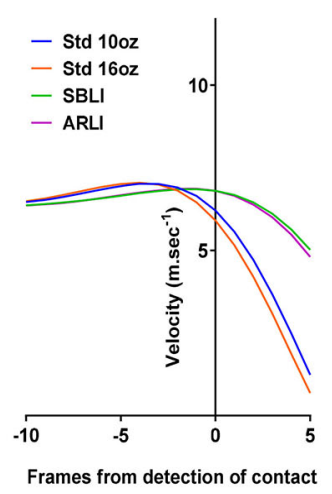

4 metres

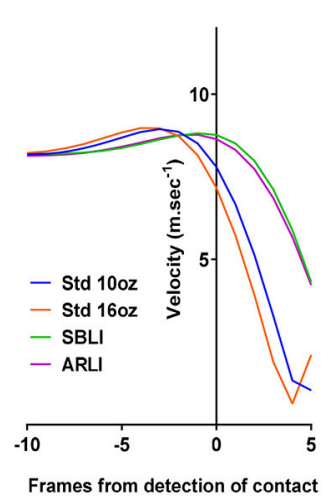

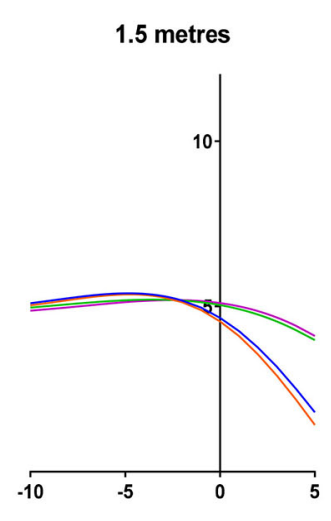

3 metres

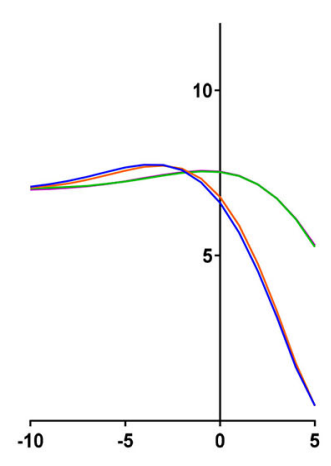

4.5 metres

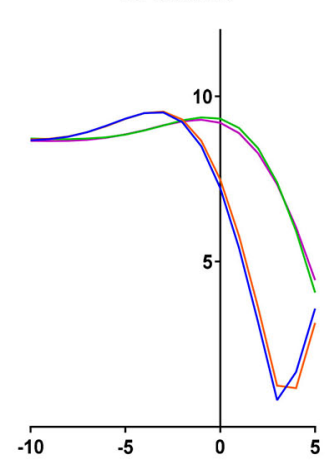

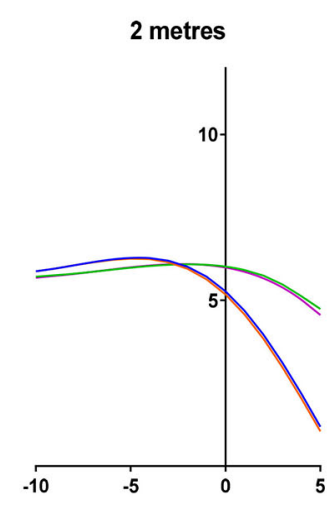

3.5 metres

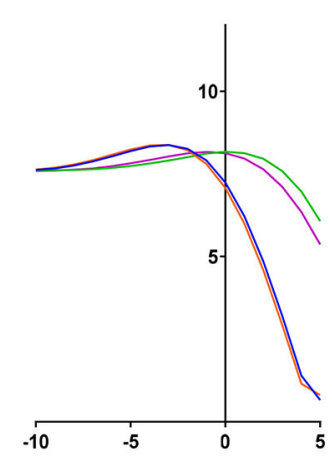

5 metres

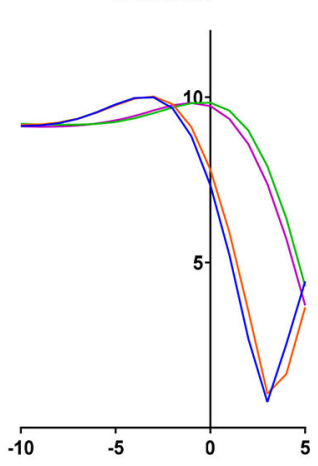

Figure 9. Velocity measurements obtained from Vicon Motion Capture System from 10 frames before to 5 frames after impact. Each curve represents an average for five glove drops.

force. Once the force did begin to rise, the increase was less steep than that observed for the conventional gloves, at least for drop heights up to and including 3.5 metres. For the ARLI glove, this remained the case right through to the drop height of 5.0 metres, and the peak impact force was always well below the levels observed for the Std $10 \mathrm{oz}$ and Std $16 \mathrm{oz}$ gloves. In the case of the SBLI glove, the delay in the onset of the rapid phase of force increase continued at drop heights of 4.0 metres and more, but beyond the point of that onset, the steepness of the curve became similar to that seen with the conventional gloves, probably because 


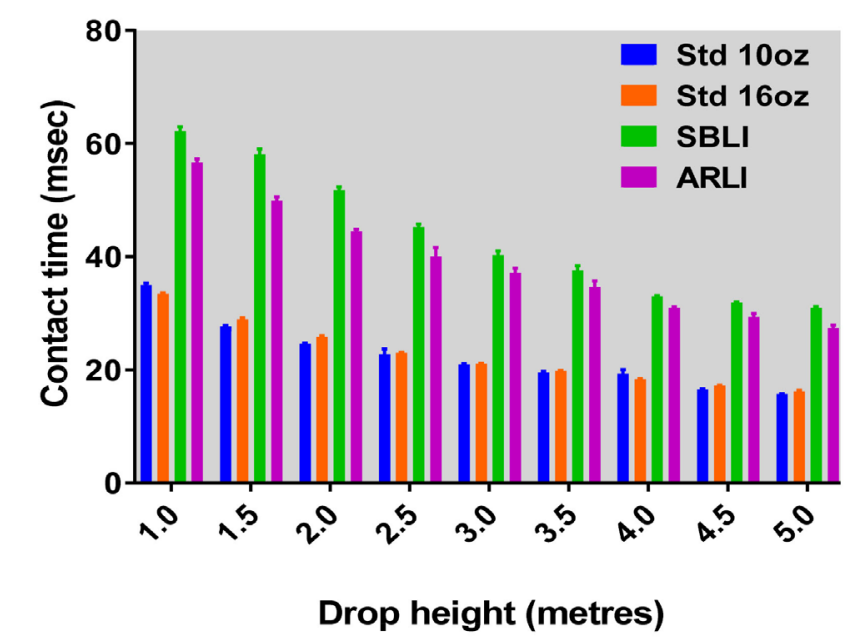

Figure 10. Contact times for different glove types and drop heights. Each bar represents a mean value for five glove drops that produced the highest peak impact forces within a series of 10 drops. Standard deviations for the five drops are also shown.

the air in the glove bladder was compressed to such an extent as to produce a "hard" glove surface.

Essentially, the impact damping capacity of the SBLI glove was substantial at low to moderate impact magnitudes but 'bottomed out' when the impact magnitudes became high.

Force measurements for dropped objects are related to total energy at impact, which is affected not just by pre-impact velocity but also by the mass of the dropped object. We used standard digital kitchen scales to determine the masses of all gloves used in the above trial. The results appear in Table 1.

Using these masses, the known mass of the mechanical fist and the measured pre-impact velocities, we calculated total impact energy for all glove types at all drop heights. The results suggested that on average the total energy would be $\sim 4.8 \%$ greater for the Std 16 oz glove than for the Std 10 oz glove and the ARLI glove, and $\sim 6.5 \%$ greater than that for the SBLI glove. To gain an indication of the actual total energy for each of trials, we employed the trapezoid method to calculate the area under the force-time curve for each drop. The mean values for each glove type and drop height are shown in Figure 12. As expected, the values were always highest for the Std $16 \mathrm{oz}$ glove. They were $~ 5.5 \%$ higher than those for the Std $10 \mathrm{oz}$ glove, which produced values very similar to those for the ARLI glove. This too conformed closely to theoretical surmise. The only anomaly concerned the SBLI glove. For this glove, the calculated area under the curve was on average only $1.6 \%$ less than that for the Std $16 \mathrm{oz}$ glove and was higher than the values for the other two gloves, whereas we had expected it be the lowest of all. The reasons for the anomaly are unclear, and experimental error cannot be excluded, although it might be relevant that the SBLI glove contained less urethane foam than any of the other gloves, possibly lessening the capacity for the glove itself to take up and temporarily store some of the energy. 

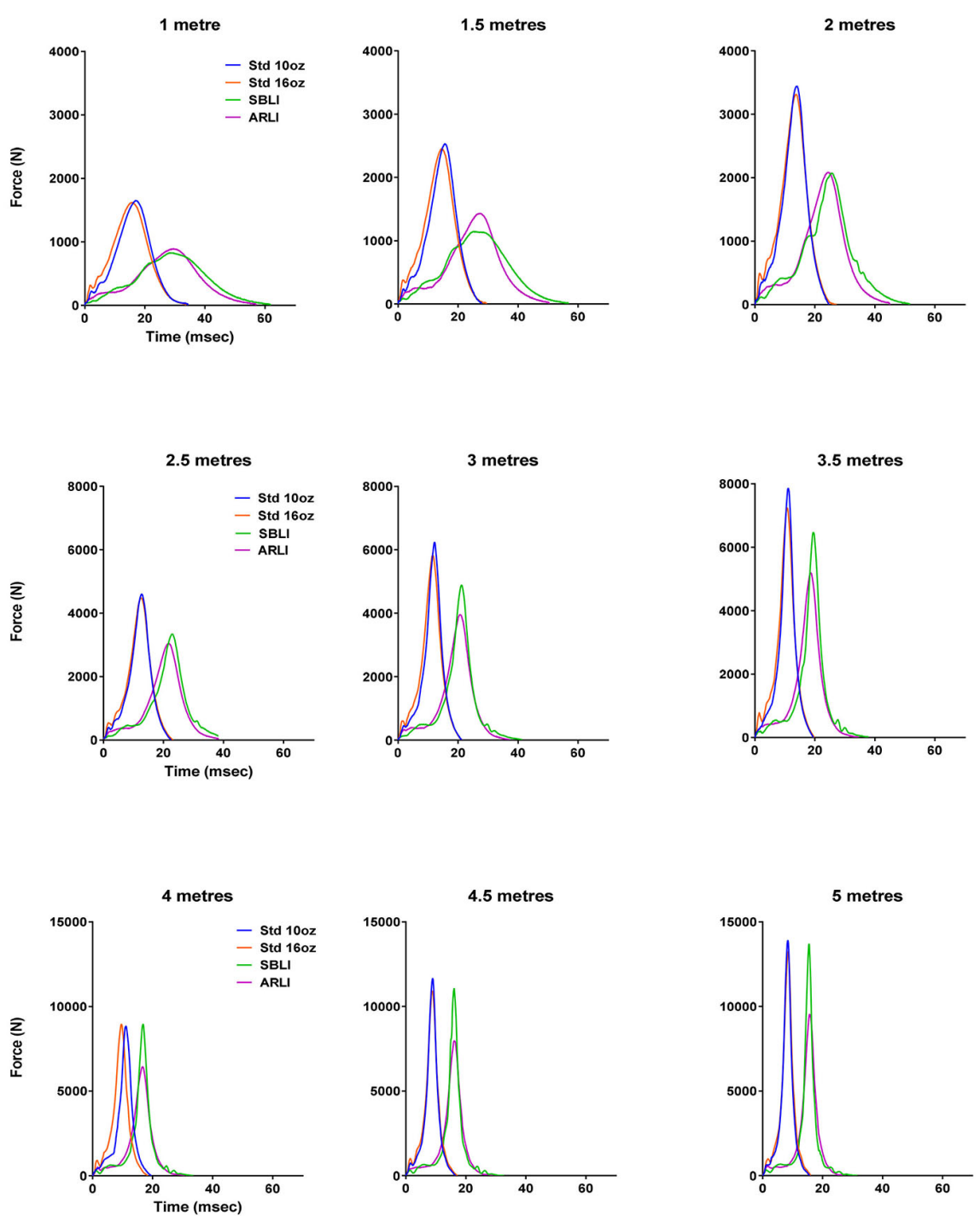

Figure 11. Force-time curves for different glove types and drop heights. Each curve relates to the glove drop that produced the third highest peak force reading from 10 drops. Note that the scales of the $y$-axis differ between the three lines of graphs.

The potential for an impact to cause injury is likely related not just to the peak impact force but could depend even more on the peak rate of force development, since the latter will affect the peak accelerative impetus imparted to the target. We therefore calculated peak rates of force development, which equates to maximum steepness of the force-time curve, for each glove type at each drop height. For every test condition, the calculation was made for the glove drops that produced the highest five peak force readings. Running mean values were calculated over $0.5 \mathrm{msec}$ intervals, advancing by $0.1 \mathrm{msec}$ each time. The mean values were then doubled to yield measures in $\mathrm{N} \cdot \mathrm{msec}^{-1}$. The results appear in Figure 13.

The effect of the ARLI glove in reducing the peak rate of force development was greater than its effect on peak impact force. The reduction relative to the Std 
Table 1. Masses of gloves as measured by digital kitchen scales.

\begin{tabular}{cc}
\hline Glove & Mass \\
\hline Std $10 \mathrm{oz}$ & $278 \mathrm{~g}(9.8 \mathrm{oz})$ \\
Std $16 \mathrm{oz}$ & $455 \mathrm{~g}(15.9 \mathrm{oz})$ \\
SBLI & $227 \mathrm{~g}(8.0 \mathrm{oz})$ \\
ARLI & $298 \mathrm{~g}(10.5 \mathrm{oz})$ \\
\hline
\end{tabular}

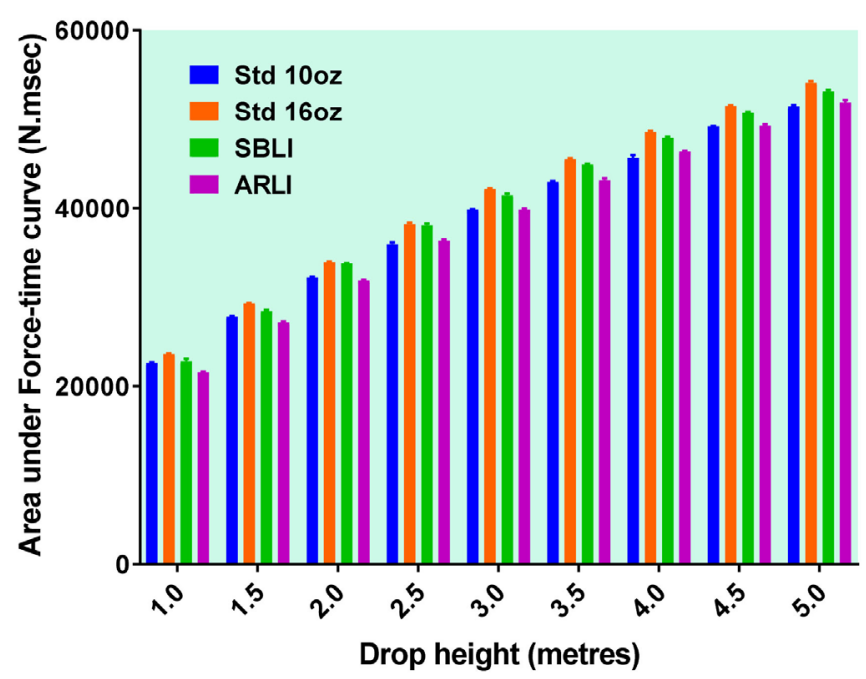

Figure 12. Calculated area under the force-time for different glove types and drop heights. Each bar indicates the mean for five glove drops that produced the highest peak forces within a series of 10 drops. Standard deviations for the five drops are also shown but are so small as to be barely perceptible.

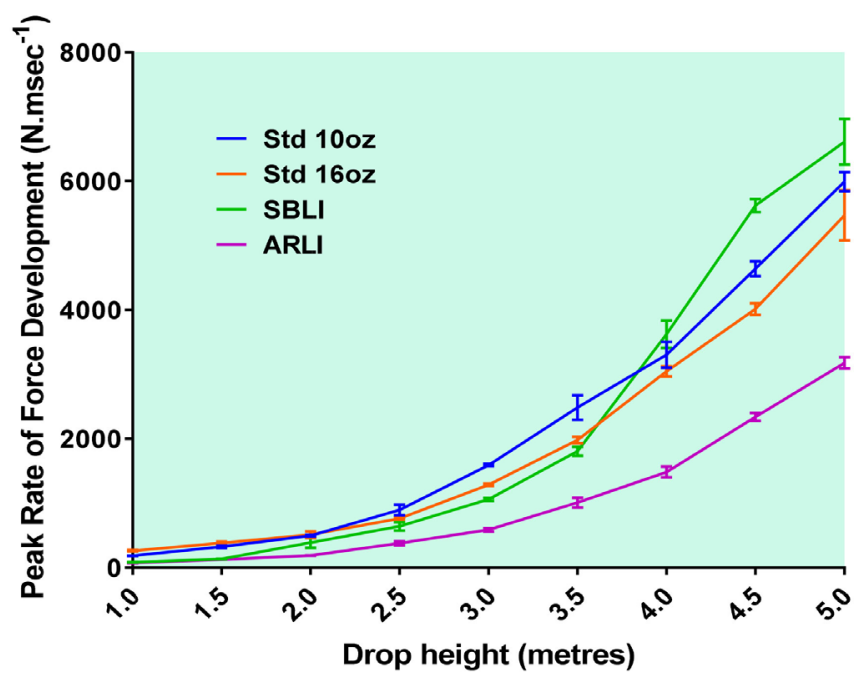

Figure 13. Peak rates of force development for various combinations of glove type and drop height. Each point on the graph represents a mean of five glove drops that produced the highest five peak impact force readings from 10 drops under the specified condition. The bars indicate standard deviations. 
$10 \mathrm{oz}$ glove was $\sim 60 \%$ at drop heights up to and including 3.5 metres and 55,50 and $47 \%$ at drop heights of 4.0, 4.5 and 5.0 metres respectively. The SBLI glove was nearly as good as the ARLI glove in decreasing the peak rate of force development at 1.0 and 1.5 metres, but its protectiveness progressively reduced from that point onwards, and at 4.0, 4.5 and 5.0 metres it yielded peak rates of force development exceeding those recorded for the Std $10 \mathrm{oz}$ and Std $16 \mathrm{oz}$ gloves. Values for the Std 16 oz glove were less than those for the Std 10 oz glove at drop heights above 2.5 metres but were still much greater than those for the ARLI glove.

\section{Discussion}

Our ARLI glove reduced peak impact forces and peak rates of force development across a wide range of impact magnitudes. The protective effects markedly exceeded those currently provided by conventional gloves, including a $16 \mathrm{oz}$ glove of the type commonly used by boxers to diminish injury risks associated with sparring. This appears to have been due to an ability of the ARLI glove to distribute impact energy over a longer contact time without ever reaching maximum compression. Although the SBLI glove had an even greater effect in prolonging contact time, the sealed nature of its air compartment apparently caused it to approach and perhaps reach maximum compression at higher impact magnitudes, with consequent loss of protective effect. Given practical limitations on the size of a bladder that can be incorporated into a glove, a capacity for air release from the bladder seems a vital inclusion for pneumatic gloves intended for employment in situations where moderate- to high-velocity impacts are likely. This accords with a design proposed by Carrillo [45] in 2006 but not by any of the prior developers of pneumatic gloves [26]-[44].

\subsection{What Range of Impact Magnitudes is Relevant?}

We found that for impacts producing peak forces up to $4500 \mathrm{~N}$ with Std $10 \mathrm{oz}$ and Std $16 \mathrm{oz}$ gloves the reductions in peak force provided by the ARLI and SBLI gloves were fairly similar. Assessment of the practical importance of the clearly superior performance of the ARLI glove beyond that point therefore requires consideration of the forces delivered by boxers in the real world. Studies aimed at quantifying these forces have yielded widely varying results. This seems largely due to variation between studies in methods of measurement and the levels of the participating athletes.

An early attempt to measure peak forces entailed use of a water-filled punching bag containing a submerged pressure sensor [54]. Increase in water pressure resulting from impact to the bag enabled calculation of forces. Mean peak impact force for 24 elite international boxers was $3453 \mathrm{~N}$ and, within this group, peak force showed a significant positive correlation with body mass. An estimate based on linear regression indicated that for every additional $\mathrm{kg}$ of body mass, peak force produced by the boxers increased by $26.6 \mathrm{~N}$. Since the mean body 
mass of the group was $69.2 \mathrm{~kg}$, it can be surmised that boxers weighing $\sim 100 \mathrm{~kg}$ would have generated peak impact forces of $\sim 4300 \mathrm{~N}$ despite some impact energy being converted into movement of the bag relative to its point of suspension. Lower mean peak forces of $3023 \mathrm{~N}$ and $2932 \mathrm{~N}$ were observed for a group of 23 national-level boxers and 23 novice boxers respectively, and in these groups there was no significant correlation between peak force and body mass.

Atha et al. [55] conducted a study involving a leading British heavyweight professional boxer who subsequently became a European and world champion and was renowned for his punching power. The boxer, wearing standard gloves of unstipulated mass, delivered punches to a target plate attached to a suspended $7 \mathrm{~kg}$ cylindrical mass. The target plate had a mass of $0.8 \mathrm{~kg}$ and was mounted on a shaft that moved freely on lubricated bearings. A piezoelectric force transducer was sandwiched between the target plate and the cylindrical mass. The front surface of the plate was padded with felt and leather. For initial trials, the padding had a thickness and yield designed to simulate characteristics of the human face, but it was subsequently found necessary to add an unspecified amount of extra padding in order for the boxer to be willing to strike the plate with maximal force. Using forces recorded for submaximal punches with and without the extra padding, a regression equation was developed to express the relationship between results for the two conditions. The boxer delivered seven maximal punches to the target plate and based on "direct hit" criteria one was selected for detailed analysis. The measured peak impact force was $4096 \mathrm{~N}$ and through application of the regression equation it was determined that this was equivalent to a force of $6320 \mathrm{~N}$ in the absence of the additional target plate padding. The ecological validity of this finding was subsequently questioned by Margetts [56] who argued that in the real world impact forces would be dampened by movement of the target, there would be significant counterforce generated by cervical muscles, and part of the impact energy would be transmitted to the torso, thereby increasing the effective mass of the target.

Using a force plate incorporating strain gauges as the measurement device, Karpilowski et al. [58] recorded a maximum impact force of $2697 \mathrm{~N}$ for a heavyweight boxer. Their paper provides no details as to how the force plate was mounted, whether its surface was padded, or the rate at which it was sampled.

Smith et al. [59] developed a punch measurement system entailing use of a wall-mounted force plate. Four triaxial piezoelectric force transducers were positioned between two rectangular aluminium sheets, one with a thickness of 25 $\mathrm{mm}$ and the other with a thickness of $50 \mathrm{~mm}$. The unit was bolted to a $400 \mathrm{~mm}$ thick mounting wall with the $25 \mathrm{~mm}$ aluminium sheet against the wall. A manikin simulating the head and upper body of a boxer was fixed to a $20 \mathrm{~mm}$ thick aluminium sheet which was then attached to the outer $(50 \mathrm{~mm})$ aluminium surface of the force plate. The manikin, which had a mass of $21.7 \mathrm{~kg}$, consisted of reconstituted chip foam within a leather covering attached to a $20 \mathrm{~mm}$ thick plywood back panel. It was designed with the aim that striking it would produce kinaesthetic sensations similar to that associated with striking an opposing 
boxer. The system was calibrated using a pendulum to which known weights could be added. In the quantification of impacts, the triaxial force transducers were sampled at $330 \mathrm{~Hz}$. Peak impact forces associated with maximal straight punches delivered by elite boxers were found to markedly exceed those delivered by intermediate and novice boxers, and within each performance level the peak forces were greater for the rear hand than the lead hand. The mean peak force for the elite boxers was $4800 \mathrm{~N}$ and one of them recorded a peak force of $5771 \mathrm{~N}$.

Subsequent studies using the measurement system of Smith et al. [58] produced comparable results. Dyson et al. [59] reported that for six competitive amateur boxers wearing $10 \mathrm{oz}$ gloves the mean peak force associated with maximal straight rear hand (dominant hand) punches to the head of the manikin was $4236 \mathrm{~N}$ with a standard error of $181 \mathrm{~N}$ (which equates to a standard deviation of $\sim 443 \mathrm{~N}$ ). Smith et al. [60] found that for members of the English senior international amateur boxing team tested under these same conditions the mean peak force was $2643 \mathrm{~N}$ with a standard deviation of $1273 \mathrm{~N}$. This suggests occurrence in both studies of individual peak force readings exceeding $5000 \mathrm{~N}$.

In an effort to enable best possible laboratory simulation of real world conditions, Walilko et al. [50] used a Hybrid III crash test manikin to study the effects of maximal straight punches to the face on the biomechanics of the head. Since the Hybrid III manikin had been engineered to closely mimic human structural characteristics, no padding of the face was required. The manikin included a segmented neck with flexible polymer discs to allow flexion-extension and lateral movements resembling those of the human neck. Seven boxers ranging in weight from 48 to $109 \mathrm{~kg}$ and wearing standard gloves each delivered three straight punches to the face of the manikin. A six-axis load cell in the upper neck of the manikin was used to measure neck forces and was sampled at 14,700 $\mathrm{Hz}$. The mean peak force for a total of 18 punches that met criteria for inclusion in the study was $3427 \mathrm{~N}$ and the highest peak force recorded by any of the boxers was $4741 \mathrm{~N}$. Peak force was significantly correlated with boxer weight, with two super heavyweights producing the highest readings.

Mack et al. [61] later used the Hybrid III manikin to measure punch forces of 42 amateur boxers competing in an international tournament, but on this occasion the sampling rate of the six-axis upper neck load cell was reduced to 10,000 $\mathrm{Hz}$. Each of the boxers delivered four punches, consisting of two straight punches and two hooks with the dominant hand. The straight punches were directed to the jaw of the manikin and the hooks were directed to the side of the manikin's head. Mean peak force values are not presented in the paper, but graphical representations reveal that with straight punching one boxer generated a peak force of just over $4500 \mathrm{~N}$ and another recorded a value of $\sim 4100 \mathrm{~N}$.

Hooked punches produced much higher peak forces, with six boxers recording measures above $5500 \mathrm{~N}$ and one attaining a reading of $8000 \mathrm{~N}$. This observation contrasted with the earlier observation of Smith et al. [60] who found that for English international amateur boxers the peak forces associated with rear-hand hooks to the head of a manikin attached to a wall-mounted force plate 
were not greater than those associated with rear-hand straight punches to the head. This difference in findings is likely due to a difference in the experimental conditions including the sophistication of the manikins.

The first attempt at quantification of peak punch forces during actual boxing matches was carried out by Pierce et al. [62]. Lightweight, flexible capacitive force sensors were inserted into $8 \mathrm{oz}$ and $10 \mathrm{oz}$ boxing gloves immediately beneath the striking surface. Within each glove, the force sensor had an effective measurement area of $120 \mathrm{~cm}^{2}$ and was connected via a thin wire to a transceiver located in the wrist region. Through radio telemetry, the transceiver could send data obtained by the sensor to a receiver located up to $35 \mathrm{~m}$ away. The accuracy of the measurements provided by the glove sensors was checked by securing instrumented gloves in a vertical position on a force plate and dropping a $3.6 \mathrm{~kg}$ padded platform on to them from various heights. This allowed the establishment of polynomial regression equations expressing the relationship between glove sensor and force plate measurements. The average error of measurement, calculated from the differences between measured forces and those determined using the regression equation, was $4 \%$ for the 8 oz glove and, although not specified, presumably of similar magnitude for the $10 \mathrm{oz}$ glove. The instrumented gloves were used by contestants in each of six professional bouts involving a total of 20 rounds. The bouts were in six different weight categories and the contestants ranged in weight from 59.0 to $99.8 \mathrm{~kg}$. For the great majority of punches delivered during the bouts, peak forces were below $2000 \mathrm{~N}$, but single highest readings for the 12 boxers averaged $3295 \mathrm{~N}$. For one boxer, the single highest reading was $5358 \mathrm{~N}$ and for another it was $5033 \mathrm{~N}$.

Taken together, the findings indicate that boxers have been capable of producing peak impact forces well above $4000 \mathrm{~N}$ and even up to $8000 \mathrm{~N}$ in laboratory simulations, depending partly on target characteristics, and that forces within this range are occasionally delivered during actual boxing competition. It is very likely that even higher peak forces can occur, since the laboratory studies involved striking of stationary objects, whereas in the real world there can be situations when the target is moving toward the impact, thereby increasing the effective velocity of the collision. Although the monitoring of professional boxing matches by Pierce et al. [62] did not reveal any peak impact forces above the highest levels observed in the laboratory studies, many of the 12 boxers who participated in those matches were inexperienced, with eight having previously participated in less than 10 bouts and four having participated in three or less bouts. Additionally, none of the six bouts ended in a knockout. It is probable that wider sampling of competitive boxing matches would occasionally reveal peak force values beyond those recorded in the initial sample.

The above suggests that to improve safety under all real-world conditions, low-impact gloves should be engineered to reduce peak impact forces of up to a 'standard glove' equivalent of at least 10,000 N. They should also be protective at levels below $2000 \mathrm{~N}$, since most punches delivered during boxing matches appear to fall into this category, and there is evidence that exposure to repeated 
impacts of relatively low force can still cause serious injury [63]. We have demonstrated that our ARLI glove meets and even exceeds these specifications.

\subsection{Importance of Peak Rate of Force Development}

There is direct relationship between the rate at which force is applied (often termed the "loading rate") and the risk of bone fractures. Tran et al. [64] subjected bovine lumbar spine segments to impacts that differed in terms of loading rates but delivered the same total amount of energy. The low loading rate caused compressive fractures and a mean spinal canal encroachment of $6.8 \%$, whereas the high loading rate produced more severe burst fractures and a mean spinal canal encroachment of 47.6\%. Ewers et al. [65] exposed knees of human cadavers to peak impact forces of $5000 \mathrm{~N}$ at high ( $5 \mathrm{msec}$ to peak) or low (50 msec to peak) loading rates. There was greater incidence of gross fractures and microfractures when the loading rate was high.

Averaged across all nine drop heights used in our experiment, the time from first contact to occurrence of peak force was $12.4 \mathrm{msec}$ for the Std $10 \mathrm{oz}$ glove and $21.5 \mathrm{msec}$ for the ARLI glove. While the difference in the time to peak was therefore less than in the research of Ewers et al. [65], it seems reasonable to suggest that the lower loading rate associated with the ARLI glove could reduce the incidence of nasal and other facial fractures that sometimes occur in boxing.

Rather than basing our analysis just on the overall time from force plate contact to peak force, we calculated the peak loading rate for any period of $0.5 \mathrm{msec}$ on the ascending phase of the force-time curve. This approach negated the possibility of drawing an erroneous conclusion that otherwise could result simply from a longer initial delay before onset of a rapid rise in force. It showed that across all drop heights the peak loading rate for the ARLI was never more than $55 \%$ of that observed with the $10 \mathrm{oz}$ glove. The conclusion that the ARLI glove is likely to be protective against bone fractures is therefore reinforced.

The loading rate also affects the likelihood of impact injuries to the chest and abdomen and the organs contained within them. Cooper and Taylor [66] have noted that the nature and severity of such injuries depends on both the magnitude of distortion of the body wall and the rate of that distortion. Substantial compression of the torso can be tolerated with minimal injury if the distortion is slow, while severe internal injury can occur with relatively little compression when there is a high distortion rate [66]. This is partly because mechanical failure of many physical structures (including many body tissues) in response to the application of force is rate-dependent. It suggests that the ability of our ARLI glove to markedly reduce loading rates compared with conventional boxing gloves can therefore be expected to decrease the risk of impact-induced chest and abdominal injuries.

The effect of loading rate on the likelihood of brain injury due to impact is less clear. This is partly because the mechanisms of brain injury are complex [67] and understanding of them is still developing [68]. Most impacts to the head 
cause it to undergo a combination of linear acceleration (acceleration in the direction of the impact) and rotational acceleration (angular acceleration relative to the head's centre of gravity). Linear acceleration produces compressive stresses that can cause substantial inward displacement of the skull with or without consequent fracture, brain contusion adjacent to the impact site and on the opposite side of the brain in line with the direction of impact, and occasionally epidural haematoma resulting from damage to meningeal blood vessels [69]. Susceptibility to injuries resulting from linear acceleration of the head appears to increase with loading rate. Viano and Lovsund [70] examined databases relating to studies entailing controlled delivery of linear impacts to the brains of ferrets and concluded that degree of injury could be best predicted by an index calculated as the product of strain and loading rate. They noted that strain alone was not a sufficient indicator of the injury risk.

Human brain tissue, however, has very low compressibility, and is therefore relatively resistant to injury caused by compressive stress. By contrast, it is highly vulnerable to shear forces [68]. Rotational acceleration of the head can generate damaging shear forces through a mechanism that has been explained by analogy of the head to a bowl of porridge, with the bowl representing the skull and the porridge representing the substance of the brain [71]. If the bowl is subjected to a direct hit on one side, the porridge moves essentially en masse toward the opposite side. If on the other hand the bowl is spun, the part of the porridge at the edge of the bowl moves with the bowl, while the part toward the centre is left behind. Consequently, there is relative motion within the porridge, demonstrating the creation of shear forces.

In the case of the brain, relative motion of the type described above can cause tearing of fixed blood vessels that run from the surface of the brain to various sinuses in the dura [69]. This can lead to subdural haemorrhage and haematoma-the most common acute cause of boxing-related deaths [72]. Early studies indicated that subdural haemorrhage typically resulted from impacts producing high angular acceleration of short duration [73]. This was thought due to an effect of loading rate on the strain threshold for failure of blood vessels [74], but based on subsequent research it seems that the threshold might be absolute, and therefore independent of loading rate [75]. Accordingly, there is now uncertainty concerning the influence of the rate of force application to the head (and consequently of the strain rate experienced by tissues exposed to the force) on the risk of subdural haemorrhage, and a question remains concerning the value of the decreased loading rates associated with our ARLI glove in protecting against this injury.

There is evidence, however, to suggest that damage to neural tissue is affected by loading rate. Galbraith et al. [76] subjected a giant axon from a squid to tensile loading and found that as the loading rate increased, the physiological response of the axon changed from a small reversible hyperpolarisation to depolarisation, and that the time taken to return from the depolarised state increased 
with the loading rate. LaPlaca et al. [77] applied shear stresses to cultured neural cells and reported that whereas slow application of stress produced no change in peak free intracellular calcium concentration, rapid stress application caused increases to 2.6 to 3.9 times the baseline level, with higher values corresponding to greater cell injury. Also, disruption of cell membranes, as indicated by lactate dehydrogenase release from the cells, increased as a function the loading rate. When the loading rate was high, lactate dehydrogenase continued to increase for 24 hours after stress administration, showing that damage was prolonged. Jin et al. [78] have reported that strain rate has a clear effect on the magnitude of tissue stress induced by compressive and shear testing of samples of human grey matter obtained from the cerebral cortex and thalamus, and of white matter obtained from the corpus callosum and corona radiata.

Analysis of data obtained from laboratory reconstruction of helmet impacts filmed during American football matches led Zhang et al. [79] to identify loading rate as likely being a key parameter in the biomechanics of concussion. For the midbrain region, the product of strain and loading rate was more than threefold higher for impacts that resulted in concussion compared to those that did not.

Although our studies included no measures of the effect of our ARLI glove on loading rate in contacted human tissues, we have demonstrated that the glove markedly reduces loading rate (measured as peak rate of force development) for a contacted force plate. It seems reasonable to assume some transfer of this effect to the tissue environment. Based on the above, a consequent reduction in the risk of brain injury could be expected but, because there is ongoing debate regarding the mechanisms of such injury [80], this is not certain.

\subsection{Could Increasing Impact Duration Have Negative Consequences?}

There is presently much public interest and concern in relation to the acute and long-terms effects of cerebral concussion. The syndrome can be due to one or more of several different types of injury, including brain contusions and diffuse damage to the axons of neurons in the cerebral hemispheres and subcortical white matter [81]. Current consensus, though, is that rotational acceleration of the head is a major aetiological factor. The magnitude of rotational acceleration required to produce concussion is inversely related to the duration of that acceleration [82], and it appears that for some types of injury associated with concussion, duration may be the predominant risk factor. In controlled studies conducted with rats, Stemper et al. [83] found that while time of recovery from an anaesthetic administered to the rats before head impact was significantly affected by the magnitude of rotational acceleration but not the impact duration, behavioural abnormalities following the impact were related more to duration than magnitude. Also, diffusion tensor imaging showed that increases in magnitude and duration produced different microstructural changes within the brain, with the effect of duration evident throughout much of the brain but par- 
ticularly at the interface of grey and white matter. It is therefore conceivable that when a decreased force loading rate occurs in association with an increased impact duration, as observed with our ARLI glove, there might not be a reduction in the risk of concussive injury but simply a change in the nature and mechanism of pathology [84].

Meaney and Smith [68] have noted that enhancement of understanding of the mechanisms of head injuries requires concurrent use of different approaches, with advanced computer modelling being complemented and progressively refined through field and laboratory research. It is therefore pertinent to consider what the different approaches can reveal as to how injury outcomes may be affected by 'softening' impacts (i.e. increasing impact compliance) in a manner resembling that achieved with our ARLI glove.

There is strong evidence that increasing impact compliance reduces peak linear and rotational acceleration associated with the impact. Oeur et al. [85] assessed relative effects of three different impact variables-compliance, velocity and location on the head-on linear and rotational acceleration measurements. A specially designed monorail drop tower was used to drop an instrumented Hybrid III headform on to three different surfaces at impact velocities ranging from 1.5 to $6.0 \mathrm{~m} \cdot \mathrm{sec}^{-1}$.

The orientation of the headform was varied to provide five distinct impact sites. The three different surfaces were steel, a $25 \mathrm{~mm}$ thickness of vinyl nitrile, and a $67 \mathrm{~mm}$ thickness of rubber foam. They were selected to encompass diverse impact conditions encountered by athletes through falls in their real-world sporting environments. Compliance was found to be inversely related to both peak linear and peak rotational acceleration, such that increased compliance reduced the acceleration magnitudes. The effect of compliance was greater than that of either velocity or impact site. It tended to be greater for rotational acceleration than for linear acceleration, whereas impact velocity-though always secondary to compliance in terms of its influence-tended to affect linear acceleration more than rotational. In view of the findings, the researchers recommended that efforts aimed at head injury avoidance in sport should prioritise increase of impact compliance above mitigation of impact velocity. This recommendation was based on previous evidence of association between acceleration measures and risk of head injury [86] [87] [88] and assumed that any protective effects of reductions in acceleration resulting from enhanced impact compliance would not be fully or more than fully counterbalanced by increased impact durations.

While noting that modern helmets have greatly decreased the incidence of traumatic brain injury caused by falls in equestrian sports, Clark et al. [89] pointed out that concussions remain common, and wondered whether this could be due to inconsistency between conditions used for testing of helmets and those experienced in real-world situations. Using the same monorail system employed in the above experiment, they dropped an instrumented Hybrid headform on to three different anvils consisting of steel, turf and sand. In each case, the peak pre-impact velocity was $5.4 \mathrm{~m} \cdot \mathrm{sec}^{-1}$. The steel anvil was in keeping with existing 
standards for helmet testing, while the turf and sand anvils were included because these are surfaces on to which equestrian riders generally fall. For each anvil type, the headform was dropped in three different configurations resulting in impact to the front, side and rear of the head. Regardless of the impact site, peak linear acceleration with turf and sand anvils was only $20 \%-26 \%$ of that observed with the steel anvil. The effect of anvil type on peak rotational acceleration varied according the headform impact site, with the readings obtained with the turf and sand anvils being $41 \%-48 \%, 20 \%-21 \%$ and $39 \%-47 \%$ of those for the steel anvil for front, side and rear head impacts respectively. Impact durations were in the range of $23-27 \mathrm{msec}$ for the turf and sand anvils and $8-9$ msec for the steel anvil. The linear and rotational acceleration measurements were used as inputs to a Finite Element Analysis model in which the scalp, skull, pia mater, falx, tentorium, cerebrospinal fluid, grey and white matter, cerebellum and brain stem were all represented. The model enabled calculation of the maximum principal strain in the cerebrum. The maximum principal strain is an index of the extent to which shear strain in the brain approaches the yield point of brain tissue as previously determined in tensile tests, and takes account of impact duration. A value of 1.0 therefore predicts gross failure of the tissue, but injury to sub-components occurs at lower levels. When the steel anvil was used, the maximum principal strain was $0.304,0.347$ and 0.310 for impacts to the front, side and rear of the head respectively. Corresponding values were 0.192, 0.125 and 0.135 for the turf anvil, and $0.190,0.135$ and 0.145 for the sand anvil. The increased impact compliance provided by the turf and sand anvils therefore appeared to lessen the risk of brain tissue injury despite the lengthening of impact duration, although the values of maximum principal strain observed with these anvils were still within the concussive range.

Very similar findings have recently been reported by de Grau Amezcua [90], who used a pneumatic device to deliver controlled impacts to five different sites on a helmeted Hybrid III headform. For every impact site, three different impact velocities $\left(4.5,6.0\right.$ and $\left.7.5 \mathrm{~m} \cdot \mathrm{sec}^{-1}\right)$ were each tested in combination with three different caps on the impactor. The caps varied in compressibility so that impacts of low, medium and high compliance could be produced. Since the study was aimed at gaining insights into head impact dynamics resulting from collisions in ice hockey, the low, medium and high compliance conditions were designed to simulate collisions with ice, the elbow of an opponent and the padded shoulder of an opponent respectively.

It was hypothesised that increasing impact compliance would reduce peak linear and rotational acceleration of the headform yet increase maximum principal strain due to longer impact duration. The expectations concerning peak linear and rotational acceleration were confirmed, but maximum principal strain was in fact substantially reduced under the high compliance condition. Averaged across the five impact sites, it never reached more than $51 \%$ of the value recorded under the low compliance condition, and at the highest impact velocity the figure was just $34 \%$. The data therefore did not support a prior notion that rela- 
tively low-intensity but long-duration impacts between heads and padded shoulders could be a major reason for a continuing high incidence of concussion in ice hockey. It appeared that any negative effect of increased impact duration resulting from higher impact compliance was more than offset by a positive effect of reduced linear and rotational acceleration.

Post et al. [91] recently conducted a study in which various acceleration-time curves previously shown to be associated with occurrence of concussion in sport environments were used as inputs to a finite element model. It was found that for each of a range of linear acceleration levels from 20 to $200 \mathrm{~g}$, maximum principal strain in the corpus callosum (a brain structure believed to be commonly affected in cases of sport concussion) increased as the duration of the impulse increased from 2.5 to $30 \mathrm{msec}$, with the duration effect becoming greater at higher levels of acceleration. The same was true for rotational accelerations varying from 1500 to 10,000 radians $\cdot \sec ^{2}$. Importantly, however, the upward drift in maximal principal strain as a function of duration was essentially complete by $15 \mathrm{msec}$. Examination of the data suggests that reducing either peak linear acceleration or peak rotational acceleration by $30 \%$ would always produce a substantial reduction in maximum principal strain in the corpus callosum, even if it was associated from with a doubling of impact duration from 15 - $20 \mathrm{msec}$ to 30 - 40 msec. These figures approximate our observations of changes produced by our ARLI glove relative to a Std $10 \mathrm{oz}$ glove for drops on to a force plate from heights of $3 \mathrm{~m}$ and above. For example, it can be ascertained that a peak rotational acceleration of 5000 radian $\cdot \sec ^{2}$ and a pulse duration of $15 \mathrm{msec}$ would lead to a maximum principal strain of 0.26 , while a peak rotational acceleration of 3500 radians $\cdot \mathrm{sec}^{2}$ and a pulse duration of $30 \mathrm{msec}$ would give a maximum principal strain of 0.19 , a reduction of $\sim 27 \%$. The reduction appears to become larger as levels of acceleration become higher. Accordingly, it is likely that our ARLI glove can lower the risk of concussive head injury resulting from any specific combination of impact velocity and effective mass within the range occurring during boxing. It has been reported, though, that maximal punches delivered by Olympic boxers to the Hybrid III headforms have produced peak rotational accelerations of almost 9000 radians $\cdot \mathrm{sec}^{2}$ with an impact duration of $10 \mathrm{msec}$ [50]. While a $30 \%$ reduction in acceleration and a doubling of duration would markedly decrease the maximum principal strain resulting from such an impact, the maximal principal strain would remain above the level denoting a 50\% risk of concussion.

Having plotted known magnitudes of 61 real-world head impacts against the durations of those impacts, Hoshizaki et al. [67] noted that incidents typically responsible for the most severe injury tended to have high relatively high impact magnitudes and short pulse durations, while those producing transient or no concussion had the opposite characteristic. Impacts that produced persistent post-concussive syndrome were generally of higher magnitude and shorter duration than those which did not. This has led Hoshizaki et al. [67] to speculate that the interaction between impact magnitude and duration may be a determinant 
of the nature, severity and mechanism of brain injury, and of the variability in symptoms. For example, in the case of rotational acceleration, impulses of high magnitude and short duration may cause the skull to move relative to the brain, creating shearing forces capable of tearing blood vessels and injuring neuronal axons, resulting in sub-dural haematoma and/or diffuse axonal injury. When the impulse is of lower magnitude and longer duration, the brain may tend to move with the skull, with stresses and strains thus transferred to the more central parts of the brain and any resultant injury less acutely dramatic.

The concept of the injury severity continuum advanced by Hoshizaki et al. [67] implies that our ARLI glove, by reducing impact magnitude and prolonging impact duration relative to the levels produced by standard boxing gloves, should shift any injury caused by impact to the head in the direction of being less severe. When this is considered in combination with the scientific literature suggesting that the ARLI glove should considerably decrease the risk of the torso injuries [66] [92] a rationale for practical deployment of the new glove seems clear.

\subsection{Acceptance of the New Glove-A Case of History Revisited?}

The development of boxing gloves employing air as an impact-damping medium has attracted the attention of inventors on a regular basis over the past 120 years [26]-[45]. Despite the efforts and ingenuity of the inventors, the development of the pneumatic gloves seems to have attracted only a small amount of media attention over the years [93] [94] [95] [96], with the coverage obtained sometimes having elements of levity, as in the case of a magazine article that raised a question as to whether in the future boxing judges would "give a man credit if he achieves a blowout but fails to achieve a knockout" [96]. It appears that none of the designs were successfully commercialised. We have been able to locate only one record of pneumatic gloves being made available for purchase, and that was through the classified advertisements section of a magazine, with the number of gloves on sale being just four [97].

Additionally, there is very little evidence of field use of pneumatic gloves. Smith [98] records that in 1916 such gloves were employed in an exhibition bout held in New York between a male and a female boxer. Because the bout contravened existing legislation it was halted by police intervention after just one round (which according to onlookers was clearly won by the female). The only substantial field usage seems to have occurred in Finland, and involved pneumatic gloves invented by Löfgren. These gloves were described in a 1957 publication [46] that also outlined the results of experiments showing that they were effective in reducing the acceleration imparted to a struck pendulum.

Over the following few years, they were reportedly used in 'hundreds of contests' conducted under the auspices of the Finnish Amateur Boxing Association, but by 1961 Löfgren [99] felt compelled to make a spirited defence of them. $\mathrm{He}$ attempted to address several major criticisms relating to the weight of the gloves (which was $12 \mathrm{oz}$ compared with the $8 \mathrm{oz}$ gloves then mandated for official 
competition), their comfort, their prevention of the ability to block punches through use of an open hand, and their cost. He also responded to a perception that the gloves had produced 'no change in the number of injuries', claiming that this was true only if analysis was confined to minor injuries such as superficial bruising and abrasions. Nevertheless, the gloves disappeared from the scene shortly afterwards.

A question arises as to whether the result is likely to be any different now. In demonstrating our ARLI gloves to members of the Australian boxing community, we have encountered reactions akin to some recorded by Löfgren [99], particularly concerning comfort, departure from the "feel" of standard gloves, a possible influence on boxing technique, and cost. An important difference, though, is the context in which we are seeking to introduce the gloves. Positioning them for use in modified boxing, rather than conventional boxing, gives the initiative a different dynamic, since participants in modified boxing tend to have a greater focus on safety and therefore may be more receptive to use of new equipment aimed at safety enhancement. Also, there is arguably a natural link between the notion of a modified sport and expectation of a requirement for deployment of modified equipment. Indeed, the availability of specialised equipment may reinforce the credibility of the modified sport.

Another point in our favour is that methods for evaluating the impact-damping qualities of gloves are now far more extensive than those that Löfgren [46] could access. Consequently, we may be able to provide more compelling evidence of the worth of our prototype glove. The force plate and motion capture research already conducted testifies to the effectiveness of the ARLI glove but in the future could be supplemented by studies entailing the use of instrumented manikins and contemporary finite element models. We envisage that ongoing generation of high-quality information in laboratory, field and virtual environments will guide progressive glove refinement and, provided that test results remain affirmative, create additional impetus for uptake of the gloves in modified boxing settings.

Acceptance and widespread use in those settings might eventually cause relevant authorities to seriously consider the applicability of the gloves to conventional boxing, but at present our fundamental objective is develop them as a means for advancing modified forms of the sport.

\subsection{Are Low-Impact Gloves Needed in Modified Boxing?}

In the version of modified boxing that we have been supporting, impacts to the head and neck are prohibited [48] [100]. Under this circumstance, a question may be asked as to whether gloves capable of reducing impact forces are needed. We believe that use of low-impact gloves in the modified boxing context is advantageous for several reasons. Experience has shown that accidental head impacts can sometimes occur, and it is important that their effects should be minimised. It is also true, however, that impacts to the torso with standard gloves have potential to be highly injurious. Oelman et al. [101] reported that amongst 
British Army personnel, boxing-related injuries were responsible for a total of 437 medical unit admissions between 1969 and 1980. While head injuries were the predominant reason for admission, with 296 cases, there were 20 admissions for trunk injuries, with the more serious cases including fractures of the ribs, larynx or vertebrae. Additionally, there were 13 admissions for internal injuries, including injuries to the kidney and pelvic organs. The average hospitalisation time for the internal injuries was 6.2 days.

Timm et al. [102] collated data from amateur boxers who sought support from medical staff for injuries sustained while training and competing at the United States Olympic Training Centre within the period from 1977 to 1992. From a total of 1219 injuries, there were 49 to the lumbopelvic region, 46 to the chest and ribs, 21 to the thorax and 10 to the abdomen. Injuries to the torso therefore constituted more than $10 \%$ of all injuries. Potter et al. [103] reported that between 1990 and 2008 there were 165,602 presentations to United States Emergency Departments for injuries sustained in boxing. Of these, $6.3 \%$ were for trunk injuries. Post-bout hematuria (blood in the urine) is common amongst boxers and is considered primarily attributable to direct kidney trauma rather than to other factors that can produce the condition [104] [105]. Rib fractures can cause damage to lung tissue, leading to pneumothorax [106], a condition in which air collects in the space between the lung and the chest wall and exerts pressure that can result in partial lung collapse. There is a case report of pneumothorax in a boxer even in the absence of rib fracture [107].

Boxing has been known to cause myocardial contusion (bruising of the heart) [108]. Blunt impact to the chest wall can cause sudden death due to cardiac arrhythmia, often in the form of ventricular fibrillation, even without injury to the ribs, sternum or heart [109] [110]. Sudden death of this nature is called commotio cordis, and typically results from impact to the left chest. There have been at least 107 cases in organised sports and recreational sports [111], including a few in boxing [109] [111] [112]. Athletes below 18 years of age are statistically the most susceptible. The impacting object is typically quite hard. In all but one of the documented sport-related cases it had a solid rather than an air-filled core [111]. Svinth [1] notes that ruptured spleens and punctured lungs have been amongst known causes of death associated with boxing.

The above makes it clear removal of the head and neck from the target zone is not of itself sufficient to make modified boxing safe, and that "softening" of impacts to the torso is also required. It is evident that our ARLI gloves can contribute importantly toward achievement of the latter objective, particularly if used in combination with other relevant measures such as athlete education and appropriately designed protective vests. In the aftermath of our experiment, the gloves have already undergone refinements to make them suitable for field use. The air exchange portal has been modified so that it does not protrude beyond the glove surface. Scope exists for further enhancement. For example, the bladder could be altered to include not just the hemispherical component but also an additional section extending over the entire back surface of the glove, thereby 
increasing overall bladder volume and perhaps augmenting the protective effect at high pre-impact glove velocities. Nevertheless, the experiment reported in this paper highlights the potential utility of appropriately designed pneumatic gloves.

\section{Conclusion}

We have produced pneumatic boxing gloves that reduce the peak magnitude of impact delivered to a target and the maximum rate of force increase. The reduction in peak force compared to conventional $10 \mathrm{oz}$ gloves currently used in boxing competitions occurs across a wide range of pre-impact glove velocities extending to the highest that world-class boxers are reportedly capable of generating and is typically in the order of $25 \%-40 \%$. The reduction in peak rate of force increase is even greater, ranging from $47 \%-63 \%$. These changes are associated with a more than $50 \%$ increase of glove-target contact times, and analysis of the available scientific literature suggests that they should substantially reduce severity of impact-induced injuries. Although the new gloves are unlikely to be rapidly adopted by the conventional boxing community, they may well prove to be almost immediately acceptable in the context of modified boxing programs that place high emphasis on safety, and this could provide a stimulus for their uptake and progressive improvement.

\section{Acknowledgements}

The work described above was supported by grants from the Australian Olympic Committee (through the Olympic Solidarity Program) and the Queensland Academy of Sport. The authors wish to acknowledge the large contribution made by the Canberra Police Community Youth Club in encouraging the first author of this paper to conduct the reported work while in its employment, and by Luke and Katie Eldridge in producing the mechanical fist that was essential to the research. The prototype low-impact gloves used in the research were expertly manufactured by Geordie Ferguson of Stellen Studio. Anthony Ashmore of AJA Engineering provided greatly appreciated technical support for the project, as did Bill Shelly of the University of Canberra and Jamie Plowman and Michael Steinebronn of the Australian Institute of Sport. Christopher Barnes of the University of Canberra provided valuable assistance with data collection. Associate Professor Stephen Trathen of the University of Canberra assisted with aspects of industrial design and Dr Richard Helmer of Superinteractive Pty Ltd offered engineering advice.

\section{References}

[1] Svinth, J. (2007) Death under the Spotlight: Analysing the Data. Journal of Combative Sport, 1-19.

[2] Lundberg, G. (1993) Medical Arguments for Nonparticipation in Boxing. In: Medical Aspects of Boxing, CRC Press, Boca Raton, 11-15.

[3] McCrory, P., Zazryn, T. and Cameron, P. (2007) The Evidence for Chronic Traumatic Encephalopathy in Boxing. Sports Medicine, 37, 467-476. 
https://doi.org/10.2165/00007256-200737060-00001

[4] Pineda, P. and Gould, D. (2010) The Neuroanatomical Relationship of Dementia Pugilistica and Alzheimer's Disease. Neuroanatomy, 9, 5-7.

[5] Jordan, B. (2000) Chronic Traumatic Brain Injury Associated with Boxing. Seminars in Neurology, 20, 179-185. https://doi.org/10.1055/s-2000-9826

[6] Cabanis, E.-A., Iba-Zizen, M.-T., Perez, G., Senegas, X., Furgoni, J., Pineau, J.-C., et al.. (2010) Boxing: Traumatology and Prevention. Bulletin De I Academie Nationale De Medecine, 194, 1219-1236.

[7] Davis, P. (1993) Ethical Issues in Boxing. Journal of the Philosophy of Sport, 94, 48-63.

[8] Hardy, J. (2013) The Ignoble Art. New Scientist, 219, 26-27. https://doi.org/10.1016/S0262-4079(13)61991-0

[9] Sugden, J. (1996) Boxing and Society. In: Boxing and Society, Manchester University Press, Manchester, 172-196.

[10] Baglio, S. (2000) The Muhammad Ali Boxing Reform Act: The First Jab at Establishing Credibility in Professional Boxing. Fordham Law Review, 68, 2257-2298.

[11] Woodward, K. (2014) Globalizing Boxing. Bloomsbury Academic, London. https://play.google.com/store/books/details?id=0SagAgAAQBAJ\&rdid=book-0SagAg $\underline{\text { AAQBAJ\&rdot=1\&source=gbs_vpt_read\&pcampaignid=books_booksearch_viewport }}$

[12] Pagelow, M.D. and Pagelow, L.W. (1984) Alternative Views on Family Violence. In: Family Violence, Praeger Publications, New York, 107. https://books.google.com.au/books?hl=en\&lr=\&id=VPPapvrJsTcC\&oi=fnd\&pg=PR $3 \& \mathrm{dq}=$ Pagelow + Pagelow + Alternative + views + on + family+violence\&ots $=\mathrm{d} 3 \mathrm{c} 4 \mathrm{lL} 1 \mathrm{kX}$ K\&sig=YkAoFif61K2JRighSsObweLw2ao

[13] The Local (2013) Sweden's Newspaper in English. Boxing Defenders Knock down Ban Proposal. http://www.thelocal.se/20130617/48536

[14] Associated Press (2013) New Norway Government to End Ban on Pro Boxing. http://www.usatoday.com/story/sports/boxing/2013/10/03/new-norway-governmen t-to-allow-professional-boxing/2919239/

[15] Warburton, N. (1998) Freedom to Box. Journal of Medical Ethics, 24, 56-60. https://doi.org/10.1136/jme.24.1.56

[16] BBC Sport Online (2000) Is Boxing a Spent Force? https://www.google.com.au/\#q=Is+boxing+a+spent+force+18+December+2000

[17] American Medical Association (1999) Boxing Injuries.

[18] Sconiers, H.E. (2017) What Are the Rules for the Ounce Sizes of Boxing Gloves? https://www.livestrong.com/article/499018-what-are-the-rules-for-the-ounce-sizesof-boxing-gloves/

[19] Johnny, N. (2010) What Boxing Gloves to Use? https://www.expertboxing.com/boxing-basics/boxing-equipment/what-boxing-glov es-to-use

[20] Stewart, J. (1890) Boxing-Glove. US421447A. https://www.google.com/patents/US421447

[21] Hilton, C.W. (1951) Thumbless Boxing Glove. US2556759A. https://www.google.com/patents/US2556759

[22] Wen-Jen, K. and Wen-Hsiung, K. (1984) Thumbless Boxing Gloves. US4425668A. https://www.google.com/patents/US4425668

[23] Yannis, A. (1982) Boxers Don't Favor Thumbless Gloves. New York Times. 
[24] Stanford, A. (1996) Boxing Glove. US5502841A. https://www.google.com/patents/US5502841

[25] Cummings, A. (2011) Uni Boxing Glove. US7904967B1. https://www.google.com/patents/US7904967

[26] Shibe, B.F. (1894) Boxing-Glove. US531872A. https://www.google.com/patents/US531872

[27] Harvey, F.A. (1896) Boxing-Glove. US570092A. https://www.google.com/patents/US570092

[28] Frazier, H.B. (1898) Boxing-Glove. US600779A. https://www.google.com/patents/US600779

[29] Baker, H.A. (1905) Boxing-Glove. US800058A. https://www.google.com/patents/US800058

[30] Dunn, A. (1913) Pneumatically-Padded Boxing Glove. US1054832A. https://www.google.com/patents/US1054832

[31] Gately, M.F. and Wells, F.N. (1925) Boxing-Glove Cushion Attachment. US1554807A. https://www.google.com/patents/US11554807

[32] Kennedy, D.J. (1927) Boxing Glove. US1622322A. https://www.google.com/patents/US1622322

[33] Slizus, J. and Kairis, M. (1938) Pneumatic Boxing Glove. US2135853A. https://www.google.com/patents/US2135853

[34] Sutherland, F.H. (1942) Pneumatic Boxing Glove. US2275206A. https://www.google.com/patents/US2275206

[35] Slizus, J. (1953) Pneumatic Boxing Glove. US2653319A. https://www.google.com/patents/US2653319

[36] Temple, R. (1956) Boxing Glove. US2740120A. https://www.google.com/patents/US2740120

[37] Vrana, C. (1958) Air Inflated Boxing Gloves. US2826757A. https://www.google.com/patents/US2826757

[38] Vrana, C. (1959) Combination Inner and Outer Inflated Boxing Glove. US2881445A. https://www.google.com/patents/US2881445

[39] Vrana, C. (1959) Air Inflated Boxing Glove. US2881446A. https://www.google.com/patents/US2881446

[40] Sweet, D.A. and Sweet, A.H. (1965) Pneumatic Boxing Glove. US3217333A. https://www.google.com/patents/US3217333

[41] Slizus, J. (1966) Pneumatic Boxing Glove. US3247520A. https://www.google.com/patents/US3247520

[42] Petrusek, V. (1973) Inflatable Boxing Glove or Pillow. US3755820A. https://www.google.com/patents/US3755820

[43] Winterbottom, H.E. (1978) Soft Punch. US4095294A. https://www.google.com/patents/US4095294

[44] Zaccaro, C. (1999) Boxing Glove. WO1999066810A1. https://www.google.com/patents/WO199906681010A1?cl=en

[45] Carrillo, H. (2006) Pneumatic Device for Boxing Gloves to Reduce Head Trauma. US7043763B2. https://www.google.com/patents/US7043763

[46] Lofgren, L. (1957) A Description of the New Pneumatic Boxing Glove. Med Sport, 11, 449-454. 
[47] Lofgren, L. (1964) The Pneumatic Boxing Glove. In: International Research in Sport and Physical Education, Charles C. Thomas, Springfield, 650-655.

[48] Hahn, A.G., Helmer, R.J., Mackintosh, C., Staynes, L.M. and Blanchonette, I. (2011) Technological Foundations and Current Status of a Modified, Low-Risk Form of Competitive Boxing (Box’Tag ${ }^{\circledR}$ ). Sports Technology, 4, 178-184. https://doi.org/10.1080/19346182.2012.725413

[49] Light-Contact Boxing. http://www.light-contact.ch/4-1-Light-Contact-Boxing.html

[50] Waliliko, T.J., Viano, D.C. and Bir, C.A. (2005) Biomechanics of the Head for Olympic Boxer Punches to the Face. British Journal of Sports Medicine, 39, 710-719. https://doi.org/10.1136/bjsm.2004.014126

[51] Muthu, J.E.R.P. (2007) Mechanics of Silicon Micro Needle Penetration in Human Cadaver Skin and Skin Substrates. Master of Science, Lehigh, Pennsylvania. https://preserve.lehigh.edu/cgi/viewcontent.cgi?article=1972\&context=etd

[52] Periyasamy, R., Anand, S. and Ammini, A.C. (2012) Investigation of Shore Meter in Assessing Foot Sole Hardness in Patients with Diabetes Mellitus-A Pilot Study. International Journal of Diabetes in Developing Countries, 32, 169-175. https://doi.org/10.1007/s13410-012-0085-z

[53] Wahnert, D., Hoffmeier, K.L., Stolarczyk, Y., Frober, R., Hofmann, G.O. and Muckley, T. (2011) Evaluation of a Customized Artificial Osteoporotic Bone Model of the Distal Femur. Journal of Biomaterials Applications, 26, 451-464. https://doi.org/10.1177/0885328210367830

[54] Joch, W., Fritsche, P. and Krause, I. (1981) Biomechanical Analysis of Punching in Boxing. In: Biomechanivs VII B: Proceedings of the Seventh International Congress of Biomechanics, University Park Press, Baltimore, 343-349.

[55] Atha, J., Yeadon, M.R., Sandover, J. and Parsons, K.C. (1985) The Damaging Punch. British Medical Journal, 291, 1756-1757. https://doi.org/10.1136/bmj.291.6511.1756

[56] Margetts, M.J. (1986) The Damaging Punch. British Medical Journal, 292, 489. https://doi.org/10.1136/bmj.292.6518.489-a

[57] Karpilowski, B., Nosarzewski, Z. and Staniak, Z. (1994) A Versatile Boxing Simulator. Biology of Sport, 11, 133-139.

[58] Smith, M.S., Dyson, R.J., Hale, T. and Janaway, L. (2000) Development of a Boxing Dynamometer and Its Punch Force Discrimination Efficacy. Journal of Sports Sciences, 18, 445-450. https://doi.org/10.1080/02640410050074377

[59] Dyson, R., Smith, M., Fenn, L. and Martin, C. (2005) Differences in Lead and Rear Hand Punching Forces, Delivered at Maximal Speed Relative to Maximal Force, by Amateur Boxers. Proceedings 23 rd International Society of Biomechanics in Sports, Beijing, 869-872.

[60] Smith, M.S. (2006) Physiological Profile of Senior and Junior England International Amateur Boxers. Journal of Sports Science and Medicine, 5, 74-89.

[61] Mack, J., Stojsih, S., Sherman, D., Dau, N. and Bir, C. (2010) Amateur Boxing Biomechanics and Punch Force.

[62] Pierce, J.D., Reinbold, K.A., Lyngard, B.C., Goldman, R.J. and Pastore, C.M. (2006) Direct Measurement of Punch Force during Six Professional Boxing Matches. Journal of Quantitative Analysis in Sports, 2, 1-17. https://doi.org/10.2202/1559-0410.1004

[63] Amen, D., Newberg, A., Thatcher, R., Jin, Y., Wu, J., Keator, D., et al.. (2011) Impact of Playing American Professional Football on Long-Term Brain Function. The Journal of Neuropsychiatry and Clinical Neurosciences, 23, 98-106. 
https://doi.org/10.1176/appi.neuropsych.23.1.98

[64] Tran, N.T., Watson, N.A., Tencer, A.F., Ching, R.P. and Anderson, P.A. (1995) Mechanism of the Burst Fracture in the Thoracolumbar Spine: The Effect of Loading Rate. Spine, 20, 1984-1988. https://doi.org/10.1097/00007632-199509150-00004

[65] Ewers, B.J., Javaraman, V.M., Banglmaier, R.F. and Haut, R.C. (2000) The Effect of Loading Rate on the Degree of Acute Injury and Chronic Conditions in the Knee after Blunt Impact. Stapp Car Crash Journal, 44, 299-313.

[66] Cooper, G.J. and Taylor, D.E.M. (1989) Biophysics of Impact Injury to the Chest and Abdomen. Journal of the Royal Army Medical Corps, 135, 58-67. https://doi.org/10.1136/jramc-135-02-04

[67] Hoshizaki, B., Post, A., Kendall, M., Karton, C. and Brien, S. (2013) The Relationship between Head Impact Characteristics and Brain Trauma. Journal of Neurology and Neurophysiology, 5, 181. https://doi.org/10.4172/2155-9562.1000181

[68] Meaney, D.F. and Smith, D.H. (2011) Biomechanics of Concussion. Clinics in Sports Medicine, 30, 19-30. https://doi.org/10.1016/j.csm.2010.08.009

[69] Kleiven, S. (2013) Why Most Traumatic Brain Injuries Are Not Caused by Linear Acceleration But Skull Fractures Are. Frontiers in Bioengineering and Biotechnology, 1, 1-5. https://doi.org/10.3389/fbioe.2013.00015

[70] Viano, D.C. and Lovsund, P. (1999) Biomechanics of Brain and Spinal Cord Injury: Analysis of Neuropathologic and Neurophysiology Experiments. Journal of Crash Prevention and Injury Control, 1, 35-43. https://doi.org/10.1080/10286589908915739

[71] McLean, A.J. and Anderson, R.W.G. (1997) Biomechanics of Closed Head Injury. In: Head Injury. Pathophysiology and Management, Chapman \& Hall Medical, London, 25-37.

[72] Sawauchi, S., Murakami, S., Tani, S., Ogawa, T., Suzuki, T. and Abe, T. (1996) Acute Subdural Hematoma Caused by Professional Boxing. No Shinkei Geka, 24, 905-911.

[73] Gennarelli, T.A. (1983) Head Injuries in Man and Experimental Animals: Clinical Aspects. Acta Neurochirurgica, 32, 1-13.

https://doi.org/10.1007/978-3-7091-4147-2_1

[74] Lowenheilm, P. (1974) Dynamic Properties of the Parasagittal Bridging Veins. Zeitschrift Fur Rechtsmedizin, 74, 55-62. https://doi.org/10.1007/BF01869185

[75] Lee, M.C. and Haut, R.C. (1989) Insensitivity of Tensile Failure Properties of Human Bridging Veins to Strain Rate: Implications in Biomechanics of Subdural Hematoma. Journal of Biomechanics, 22, 537-542. https://doi.org/10.1016/0021-9290(89)90005-5

[76] Galbraith, J.A., Thibault, L.E. and Matteson, D.R. (1993) Mechanical and Electrical Responses of the Squid Giant Axon to Simple Elongation. Journal of Biomechanical Engineering, 115, 13-22. https://doi.org/10.1115/1.2895464

[77] LaPlaca, M.C., Lee, V.-Y. and Thibault, L.E. (2009) An in Vitro Model of Traumatic Neuronal Injury: Loading Rate-Dependent Changes in Acute Cytosolic Calcium and Lactate Dehydrogenase Release. Journal of Neurotrauma, 14, 355-368. https://doi.org/10.1089/neu.1997.14.355

[78] Jin, X., Zhu, F., Mao, H., Shen, M. and Yang, K.H. (2013) A Comprehensive Experimental Study on Material Properties of Human Brain Tissue. Journal of Biomechanics, 46, 2795-2801. https://doi.org/10.1016/j.jbiomech.2013.09.001

[79] Zhang, L., Yang, K.H., King, A. and Viano, D.C. (2003) A New Biomechanical Predictor for Mild Traumatic Brain Injury-A Preliminary Finding. Summer Bioengi- 
neering Conference, Key Biscayne, 137-138.

[80] King, A.I., Yang, K.H., Zhang, L. and Hardy, W. (2003) Is Head Injury Caused by Linear or Angular Acceleration? IRCOBI Conference, Lisbon, September 2003, $1-12$.

[81] Pearce, J.M.S. (2008) Observations on Concussion. European Neurology, 59, 113-119. https://doi.org/10.1159/000111872

[82] Rousseau, P. (2014) Analysis of Concussion Metrics of Real-World Concussive and Non-Injurios Elbow and Shoulder Head Collisions in Ice Hockey. PhD, University of Ottawa, Ottawa. https://ruor.uottawa.ca/bitstream/10393/31524/3/Rousseau_Philippe_2014_thesis.pdf

[83] Stemper, B.D., Shah, A.S., Pintar, F.A., McCrea, M., Kurpad, S.N., Glavaski-Joksimovic, A., et al.. (2015) Head Rotational Acceleration Characteristics Influence Bevavioral and Diffuse Tensor Imaging Outcomes Following Concussion. Annals of Biomedical Engineering, 43, 1071-1088. https://doi.org/10.1007/s10439-014-1171-9

[84] Willinger, R., Taleb, L. and Kopp, C.M. (1995) Modal and Temporal Analysis of Head Mathematical Models. Journal of Neurotrauma, 12, 743-754. https://doi.org/10.1089/neu.1995.12.743

[85] Oeur, R.A. and Hoshizaki, T.B. (2016) The Effect of Impact Compliance, Velocity, and Location in Predicting Brain Trauma for Falls in Sport. IRCOBI Conference, Malaga, 14-16 September 2016, 228-238.

[86] Pellman, E.J., Viano, D.C., Tucker, A.M., Casson, I.R. and Waeckerie, J.F. (2003) Concussion in Professional Football: Reconstruction of Game Impacts and Injuries. Neurosurgery, 53, 799-814. https://doi.org/10.1093/neurosurgery/53.3.799

[87] Zhang, L., Yang, K.H. and King, A.I. (2004) A Proposed Injury Threshold for Mild Traumatic Brain Injury. Trans ASME, 126, 226-236. https://doi.org/10.1115/1.1691446

[88] Rowson, S. and Duma, S.M. (2013) Brain Injury Prediction: Assessing the Combined Probability of Concussion Using Linear and Rotational Head Acceleration. Annals of Biomedical Engineering, 41, 873-882. https://doi.org/10.1007/s10439-012-0731-0

[89] Clark, J.M., Post, A., Connor, T.A., Hoshizaki, T.B. and Gilchrist, M.D. (2016) Effect of Impact Surface on Equestrian Falls. 34th International Conference on Biomechanics in Sports, Tsukuba, 18-22 July 2016, 395-398.

[90] De Grau Amezcua, S. (2017) Effects of Striker Compliance on Dynamic Response and Brain Tissue Strain for Helmeted Ice Hockey Impacts. Masters, University of Ottawa, Ottawa.

[91] Post, A., Hoshizaki, T.B., Gilchrist, M.D. and Cusmano, M.D. (2017) Peak Linear and Rotational Acceleration Magnitude and Duration Effects on Maximum Principal Strain in the Corpus Callosum for Sport Impacts. Journal of Biomechanics, 61, 183-192. https://doi.org/10.1016/j.jbiomech.2017.07.013

[92] Lau, I.V. and Viano, D.C. (1986) The Viscous Criterion-Bases and Applications of an Injury Severity Index for Soft Tissues. Society of Automotive Engineers, Report No. 861882, 123-142. https://doi.org/10.4271/861882

[93] North Otago Times (1912) Pneumatic Boxing Glove.

[94] Popular Science Monthly (1930) Air Pads These Boxing Gloves. 35.

[95] Popular Science (1939) Pneumatic Boxing Glove Cushions Punches. 134.

[96] Sports Illustrated (1957) A Fistful of Air. 
[97] Popular Mechanics (1964) Pneumatic Boxing Gloves. 69.

[98] Smith, M. (2014) A History of Women's Boxing. Rowan \& Littflefield, Lanham, 346 p.

[99] Lofgren, L. (1961) The Pneumatic Boxing Glove and Protection against Skull and Brain Injuries. The Journal of Sports Medicine and Physical Fitness, 1, 23-27.

[100] Perkins, P., Helmer, R.J.N., Mackintosh, C. and Hahn, A.G. (2017) Reflections on Long-Term Development and Use of Automated Scoring Technology in a Sport (Modified Boxing) Context. World Journal of Engineering and Technology, 5, 455-480. https://doi.org/10.4236/wjet.2017.53040

[101] Oelman, B.J., Rose, C.M.E. and Arlow, K.J. (1983) Boxing Injuries in the Army. Journal of the Royal Army Medical Corps, 129, 32-37. https://doi.org/10.1136/jramc-129-01-10

[102] Timm, K.E., Wallach, J.M., Stone, J.A. and Ryan, E.J. (1993) Fifteen Years of Amateur Boxing Injuries/Illnesses at the United States Olympic Training Center. Journal of Athletic Training, 28, 330-334.

[103] Potter, M.R., Snyder, A.J. and Smith, G.A. (2011) Boxing Injuries Presenting to U.S. Emergency Departments, 1990-2008. American Journal of Preventive Medicine, 40, 462-467. https://doi.org/10.1016/j.amepre.2010.12.018

[104] Kleiman, A.H. (1958) Hematuria in Boxers. JAMA, 168, 1633-1640. https://doi.org/10.1001/jama.1958.03000120039007

[105] Jones, G.R. and Newhouse, I. (1997) Sport-Related Hematuria: A Review. Clinical Journal of Sport Medicine, 7, 119-125. https://doi.org/10.1097/00042752-199704000-00008

[106] Liman, S.T., Kuzucu, A., Tastepe, A.I., Ulasan, G.N. and Topcu (2003) Chest Injury Due to Blunt Trauma. European Journal of Cardio-Thoracic Surgery, 23, 374-378. https://doi.org/10.1016/s1010-7940(02)00813-8

[107] Belham, G.J. and Adler, M. (1985) Case Report: Pneumothorax in a Boxer. British Journal of Sports Medicine, 19, 45. https://doi.org/10.1136/bjsm.19.1.45

[108] Bellotti, P., Chiarella, F., Domenicucci, S., Lupi, G. and Vecchio, C. (1992) Myocardial Contusion after a Professional Boxing Match. American Journal of Cardiology, 69, 709-710. https://doi.org/10.1016/0002-9149(92)90175-X

[109] Vincent, G.M. and McPeak, H. (2000) Commotio Cordis. The Physician and Sportsmedicine, 28, 31-39. https://doi.org/10.3810/psm.2000.11.1285

[110] Link, M.S. (2003) Mechanically Induced Sudden Death in Chest Wall Impact (Commotio Cordis). Progress in Biophysics \& Molecular Biology, 82, 175-186. https://doi.org/10.1016/S0079-6107(03)00014-2

[111] Maron, B.J., Gohman, T.E., Kyle, S.B., Estes, N.A.M. and Link, M.S. (2002) Clinical Profile and Spectrum of Commotio Cordis. JAMA, 287, 1142-1146. https://doi.org/10.1001/jama.287.9.1142

[112] Unterharnscheidt, F. and Taylor-Unterharnscheidt, J. (2003) Injuries to Internal Organs. In: Boxing Medical Aspects, Academic Press, London, 217-223. https://doi.org/10.1016/B978-012709130-3/50051-1 